\title{
Rise and fall of vegetation primary production resilience to climate variability anticipated by a large ensemble of Earth System Models' simulations.
}

non-peer reviewed preprint submitted to EarthArXiv

Matteo Zampieri ${ }^{1 *}$, Bruna Grizzetti ${ }^{1}$, Andrea Toreti ${ }^{1}$, Pierluca De Palma ${ }^{2}$ and Alessio Collalti ${ }^{3}$

${ }^{1}$ European Commission - Joint Research Centre (JRC), Ispra IT

${ }^{2}$ Fincons SPA, Vimercate IT

${ }^{3}$ Institute for Agriculture and Forestry Systems in the Mediterranean, National Research Council of Italy (CNR-ISAFOM), Perugia (PG), Italy

*matteo.zampieri@ec.europa.eu 


\begin{abstract}
Climate change is affecting many aspects of natural ecosystems and society. Anticipating the changes in vegetation resilience - the plants' capacity to cope with disturbances and shocks such as those related to climate variability and extremes - is critical to understand and project ecosystems' responses to global change and the impacts on the related ecosystem services, to support mitigation actions, and to define proper adaptation plans.
\end{abstract}

Here, we quantify vegetation gross primary production (GPP) resilience by computing the annual production resilience indicator from the state-of-the-art Earth System Model (ESM) simulations included in the newest Sixth Phase of the Coupled Model Intercomparison Project (CMIP6). Taking the present period (1985-2014) as reference, we estimate the GPP resilience changes for different periods in the near and far future (2021-2050 and 2051-2100) under three scenarios of socioeconomical global changes, corresponding to different levels of greenhouse gases' emissions and land-use.

In the 'Sustainability (Taking the Green Road)' and 'Middle of the Road' scenarios considered here (ssp126 and ssp245), the areas where vegetation shows increasing GPP resilience (mainly boreal, African and Indian monsoonal regions) are wider than the areas with decreasing resilience. The situation drastically reverses in the 'Fossil-fuel Development (Taking the Highway)' scenario (ssp585), mostly because the increase of GPP interannual variability outbalances the mean increase due to the $\mathrm{CO} 2$ fertilization effect in this high greenhouse gases' emission scenario. Among the larger countries, Brazil is exposed to the highest risk of experiencing years with anomalously low GPP, especially in the 'Taking the Highway' scenario.

\title{
Introduction
}

Stable ecosystems, characterized by small variations from their average state despite changes in environmental conditions, are generally considered healthy and reliable in terms of the services they provide (Costanza et al., 2014; MAE, 2005; Seddon et al., 2019). Ecosystems in good condition are necessary to secure the sustainability of human activities and human well-being (Maes et al., 2020). There is currently great concern about the stability and resilience of both natural and human-managed ecosystems, particularly given the many global changes that are already occurring, such as land use and climate change (IPBES, 2018; Williams et al., 2014). The Sustainable Development Goals, formally embraced by the 2010 Conference of Parties, recognize the importance of ensuring conservation, restoration and sustainable use of terrestrial ecosystems and their services, and strengthening the resilience and adaptive capacity to climate-related hazards (SDG 15 and SDG 13, respectively; United Nations 2016).

The concept of resilience is closely connected to ecosystem stability. Resilience has been defined either as the larger disturbance that a system can absorb without losing its structure, relationships and functionalities (Holling, 1996, 1973) or as the time required by an ecosystem to recover and return back to the equilibrium state after a disturbance (Pimm, 1984). These definitions are termed 'ecological resilience' and 'engineering resilience', respectively. On the one hand, ecological resilience is a very powerful concept as it comprehensively accounts for the complexity of the ecosystem structure (e.g., total biomass, population distribution, diversity) and function (e.g., primary production, pollination) but is difficult to define quantitatively (Oliver et al., 2015). On the other hand, the engineering definition of resilience is more specific in suggesting a quantitative measurement method that was inherited by the classical theory of population dynamical systems such as the Lotka-Volterra model (Lotka, 1920; Volterra, 1926).

In the case the ecosystem analysis is focused to gross primary production (GPP), the two definitions of resilience can be in principle consistent between each other (Zampieri, 2021). GPP 
- the total carbon fixation by plants - is a primarily important terrestrial ecosystem function, at the point that it was also considered as a proxy of resilience itself (Moore et al., 1993). This essential biological process provides the base of the net primary production determining the plant growth and the main input for the food chain of myriad animal consumers including humans (Richmond et al., 2007; Vargas et al., 2019). GPP also controls the rate at which carbon dioxide is removed from the atmosphere while being at the same extremely sensitive to climate anomalies itself (Ciais et al., 2005; Raupach et al., 2007; Seddon et al., 2016).

Assessing the changes of vegetation GPP resilience of vegetation GPP in the future climate scenarios is of capital importance. Climate change is indeed expected to alter vegetation GPP resilience by potentially compromising the availability of water for natural vegetation and agriculture in dry regions (Betts et al., 2018; Stuart-Haëntjens et al., 2018; Zampieri et al., 2019) and in general by increasing the frequency, amplitude and duration of extreme events that are detrimental for vegetation productivity (Dosio et al., 2018; Naumann et al., 2018; Pokhrel et al., 2021; Toreti et al., 2019). At the same time, the increase of atmospheric $\mathrm{CO}_{2}$ concentration coming along with global warming is expected to bring positive effects in terms of vegetation photosynthetic rate i.e. the so called ' $\mathrm{CO}_{2}$ fertilization effect' (Sage and Kubian, 2007) and water use efficiency (Peters et al., 2018), although uncertainties remain (e.g. on acclimation) and the positive effects are expected to level off at around 600ppm (Bastos et al., 2020; Toreti et al., 2020).

To better represent the interactions between climate and vegetation primary production, climate models recently evolved in a direction that includes a comprehensive dynamical representation of the carbon cycle, amongst other development lines (Randall et al., 2019). Since the early 1990s, General Circulation Models (GCMs) estimate the solution to three-dimensional differential equations of fluid motion and thermodynamics to obtain time and space dependent values for temperature, winds and currents, moisture and/or salinity and pressure in the atmosphere and ocean (Mitchell et al., 1995; Murphy, 1995; Sausen et al., 1988).

The importance of an accurate and interactive representation of land surface processes such as surface hydrology as well as the role of vegetation in modulating energy and water budgets and determining relevant surface variables such as temperature and soil moisture was soon recognized (Bonan, 1998; Dickinson et al., 1998). Although the spatial resolution of the GCMs grid could have been rather low, it is worth noting that these models accounted for the sub-grid variability of vegetation, land-use, water bodies and bare ground using often very generic traits to describe vegetation, the so-called Plant Functional Types (PFTs) that divides vegetation in very broad climatic (tropical, temperate, boreal), leaf kind (broad and needle) and phenological (deciduous, evergreen) classes, C3 and C4 grasses and crops whose spatial distribution was estimated from satellite data (Loveland and Belward, 1997). Within a grid, multiple PFTs compete for water and nutrients (see references in Table 1).

The structural evolution of GCMs towards the Earth System Models (ESMs), capable of a comprehensive simulation of carbon dynamics and fluxes in the, ocean and land, occurred relatively recently (Dahan, 2010; Randall et al., 2019). The land surface component of the ESMs include a prognostic representation of the biosphere that is capable to simulate plant physiological processes such as canopy and leaf processes determining radiative transfer, photosynthesis (i.e. the GPP) as well as evapotranspiration, carbon and nitrogen cycling depending of climate variables and $\mathrm{CO}_{2}$ levels for each PFTs (Koven et al., 2013; Lawrence et al., 2019; Riley et al., 2011; Thornton et al., 2007). ESMs can estimate vegetation GPP dynamics under different climate changes scenarios providing us with the possibility of estimating the possible future gains and losses of vegetation GPP resilience.

A large number of indicators has been proposed to quantitatively measure vegetation resilience (De Keersmaecker et al., 2014a; Meyer, 2016; Scheffer et al., 2015). However, most global and regional studies estimating the impacts of climate change on vegetation productivity focus on stability i.e. the changes in GPP mean and variability due to climate extremes (Dass et al., 2016; 
Kimball et al., 2009; Verduzco et al., 2018; Williams et al., 2014; Xu et al., 2020). Other studies considering future climate projections often focus on the change of mean GPP (Madani et al., 2018; Williams et al., 2014). To our knowledge no study focused specifically on GPP resilience changes yet.

In this study, we apply the annual production resilience indicator (Zampieri et al., 2019) to the GPP data generated by the new ensemble of Earth System Models simulations (ESMs, publicly accessible at https://pcmdi.Inl.gov/CMIP6/) included in the Sixth Coupled Models Intercomparison Project (CMIP6, https://www.wcrp-climate.org/wgcm-cmip/wgcm-cmip6) of the Intergovernmental Panel on Climate Change (IPCC). The annual production resilience indicator $\left(R_{p}\right)$, defined as the squared mean GPP divided by its variance, allows characterizing the resilience of a production time-series with a single number (Zampieri et al., 2019). $R_{p}$ is a simple indicator that offers several advantages. It is inversely proportional to the risk of production losses consistently with the ecological definition of resilience (Hollings 1973) and in principle with the engineering definition as well (Zampieri, 2021). It increases with vegetation diversity (number of species) and it accounts for memory effects, i.e., for perturbation recovery timings longer than a season (Zampieri et al., 2020c).

We quantify the changes in resilience of the GPP production in the near and far future (2021-2050 and 2051-2100) under three scenarios of socio-economical global changes, corresponding to different levels of greenhouse gases emissions and land-use, i.e. the 'Sustainability', the 'Middle of the Road' and the 'Fossil-fuel Development' scenarios. The adopted indicator and the involved ESMs simulations are described in detail in the Methods section (with additional information on the mathematical theory and properties of the resilience indicator provided in the Supplementary Material, Appendix A). The global changes in vegetation gross primary production resilience in two different periods in the future and according to three different scenarios are presented in the Results section, with reference to period 1985-2014, along with biome and country level estimates that are mainly provided in the Supplementary Material (Appendix B). Finally, in the Discussion section, the results of the study are examined in view of the ambitions of the sustainable development goals (SDGs).

\section{Data and Methods}

The definitions of resilience considered in this study refer to the ability of a system to absorb external stresses maintaining its normal functioning (ecological definition), or to recover quickly from shocks (engineering definition) (Holling, 1996, 1973; Pimm, 1984). These definitions are conceptually clear but they do not directly provide a practical way to measure resilience (Morecroft et al., 2012; Quinlan et al., 2016; Scheffer et al., 2015). In fact, a quantitative estimation of resilience requires objective methods to identify and measure the external stresses and shocks (Meyer, 2016). Also as a result of such indeterminacy, a large number of indicators was proposed to measure different aspects of resilience (De Keersmaecker et al., 2014b; Meyer, 2016; Scheffer et al., 2015; Srinivasa Rao et al., 2018).

The vegetation ability to withstand environmental perturbations (i.e. ecological resilience) can be assessed from the deviation from the seasonal climatology of vegetation above-ground biomass and proxies such as the Normalized Differential Vegetation Index (NDVI) after an environmental disturbance (Lloret et al., 2007; Van Ruijven and Berendse, 2010; Vogel et al., 2012). Such operation can be conveniently conducted after normalizing the anomalies by the mean climatological values, in order to account for the ecosystem's capacity to change (De Keersmaecker et al., 2014b).

The rate of return to the equilibrium state after a perturbation (i.e. engineering resilience) can be measured by the temporal autocorrelation of relevant vegetation variables (Dakos et al., 2012), by variance of the frequency spectrum of the anomaly time series (Zaccarelli et al., 2013), or by the spectral scaling component is given by the slope of the logarithm of the spectrum upon the 
logarithm of the reverse frequency (Peng et al., 1995; Telesca et al., 2008). Up to date, none of these methods has been used to evaluate vegetation resilience at the global level and in future climate scenarios yet.

The stability of the vegetation time-series can be more easily evaluated by the absolute or normalized variance (Pimm, 1984), the latter being known as coefficient of variance. The coefficient of variance has been recently used to evaluate the effects of current climate variability on vegetation gross primary production (Chen et al., 2019; Fibbi et al., 2019; Xiao et al., 2016).

A simple and effective method, still based of a function of the mean and the variance like the coefficient of variance, but consistent with the ecological definition of resilience, was recently proposed to evaluate the production resilience of natural vegetation (Zampieri et al., 2019) and agricultural systems (Zampieri et al., 2020c). This approach is based on two assumptions (Zampieri, 2021). For annual production systems such as agriculture or natural ecosystems that are sufficiently adapted to the environmental conditions and to the local climate, it is sensible to assume that the largest disturbances are rarer compared to the "normal" conditions (assumption 1) and that the largest disturbances result in larger impacts of the annual production values (assumption 2). Under such conditions, the size of the disturbance can be univocally measured by its rareness e.g. the return period of production anomalies $\left(\mathrm{T}^{*}\right)$. It is worth noticing that $\mathrm{T}^{*}$ is the expected average number of years that pass between production losses of same size i.e. the inverse of the frequency (not to be confused with the restoring time to the equilibrium in the engineering definition of resilience). The ecological resilience can be then simply measured by $\mathrm{T}^{*} \mathrm{MAX}$, which is the return period of the largest adverse event that the system can cope with before losing completely the production ability (Zampieri et al., 2020c).

For homogeneous agricultural production systems, $T^{*} \mathrm{MAx}$ is proportional to the annual production resilience indicator, defined as:

(1) $R_{p}=\mu^{2} \sigma^{-2}$,

where $\mu$ is the mean and $\sigma$ is the standard deviation of the annual production (Zampieri et al., 2020c; Zampieri et al., 2019).

For heterogenous production systems, $R_{p}$ is linearly depending on the number of crops having the same mean production and variance, if the production fluctuations around the mean value are uncorrelated among them, and accounts consistently for different levels of cross-correlations, different mean productions and production variances characterizing diversified production systems (see Appendix A). In case the annual production resilience indicator is evaluated over a region including bare ground, the indicator is sensitive to the vegetated portion only (Zampieri et al., 2019).

Equation 1 can be easily generalized for non-stationary production systems, where the production mean and the standard deviation are not constant during the period spanned by the production time-series (Zampieri et al., 2020a). The code for handling the full problem of a diversified and nonstationary crop production systems is public and freely usable (Zampieri et al., 2020b).

In this study, $R_{P}$ was computed on a large ensemble of data composed of all the climate change simulations for vegetation gross primary production available from all the Earth System Grid Federation (ESGF) portals up to $31^{\text {st }}$ December 2019 for both the historical period and the climate scenarios, The climate scenarios included the 'Sustainability (Taking the Green Road)' (ssp126), the 'Middle of the Road' (ssp245) and the 'Fossil-fuel Development (Taking the Highway)' (ssp585) scenarios, and were evaluated considering two periods, 2021-2050 and 2051-2100, representing the near and far future periods respectively. The full list of simulations is provided in Table 1, along with the detailed reference to the land surface component of the Earth System Models. 
These land surface models include a simplified representation of the biosphere with prognostic vegetation processes such as evapotranspiration, photosynthesis, carbon allocation and growth of leaves, stems and roots interacting with near surface meteorological variables such as temperature, radiation, wind and $\mathrm{CO}_{2}$ concentration, and soil variables such as moisture, carbon and nitrogen (see references in Table 1). Therefore, in the scenarios simulation gross primary production (GPP) variability is the result of both bio-geophysical and bio-geochemical processes such as soil moisture dynamics and energy budget, permafrost thawing, atmospheric $\mathrm{CO}_{2}$ fertilization and nitrogen limitation as well as land use changes defined as a function of the different future scenarios.

Differently from the above listed processes, Land-use changes are prescribed and are the same for all CMIP6 models (Hurtt et al., 2020). The fraction of natural vegetation changes according to the different socio-economic scenarios, but the fraction of PFTs within the grid remains constant for most models, so vegetation dynamics (i.e. spatial shifts of vegetation patterns) is not considered nor is it the internal structure of the vegetated units in terms of age of the plants' population, which is not explicitly resolved. Despite this limitation, prognostic vegetation models offer a realistic representation of the vegetation growth and of relevant variables such as the leaf area index (LAl) determining the amount of intercepted radiation, albedo and other parameters affecting the local climate as well as the carbon and nitrogen cycling.

The effects of pests and diseases are not considered, however, some of the models include the effects of peculiar abiotic disturbances such as fire (Seo and Kim, 2019). Thus, they can in principle account for two type of ecological memory (Johnstone et al., 2016; Ogle et al., 2015), which are the PFTs' adaptive response to the disturbances and the effect of the disturbances on nutrients. Memory effects linked to antecedent drought conditions (Liu et al., 2018; van der Molen et al., 2011) are well reproduced since soil moisture dynamics and the related physical feedbacks were quite well developed already in the GCMs (Seneviratne et al., 2013, 2010), which are the predecessors of the ESMs and from which ESMs inherits the representation of abiotic processes.

In general, ESMs provide a reasonable representation of the GPP response to drought (see citations in Table 1), which is, however, largely variable among models (Huang et al., 2016; Knauer et al., 2015; Orth et al., 2020). This motivates the use of a large ensemble for a robust assessment of GPP changes such as the one used here.

The annual GPP is derived by summing up monthly GPP outputs for each simulation listed in Table 1 consistently with the spatial variability of vegetation seasonality (Peano et al., 2019). This procedure is especially relevant in the Southern Hemisphere and consists of computing the annual GPP using the month with minimum GPP as boundary of the temporal window where the summation is performed, which is spatially varying, instead of using a unique time window ranging from January to December.

The spatial resolution of the ESMs is different. Therefore, the annual GPP data of each simulation is interpolated on a common 0.5 degrees regular grid with a conservative remapping method (Jones, 1999). The simulations' ensemble mean $R_{p}$ is computed for each the ESMs and for each period and scenario. Finally, the overall median of the RP changes with respect to the historical period are computed for each future period and scenario.

The robustness of the results is assessed by highlighting the areas where at least $75 \%$ of the models agree on the sign of changes (models' agreement constraint). We present the results of this analysis on global maps and by computing country level aggregates, which we discuss for the largest countries and for the countries displaying the largest changes of vegetation resilience (Table S3).

Figures S1, S2 and S3 in Supplementary Material show the ensemble model results for the GPP mean, standard deviation and resilience, which can be qualitatively compared with observed 
estimates of the vegetation resilience based on remote sensing data (Zampieri et al., 2019). Figures S4 provide S5 the changes of the mean GPP and in the GPP variability, which can be compared with other studies (Dass et al., 2016; Kimball et al., 2009; Madani et al., 2018; Verduzco et al., 2018; Williams et al., 2014; Xu et al., 2020).

Distinguishing between changes in the mean and in the variability of GPP as the main drivers of changes of vegetation resilience could be useful to plan targeted adaptation strategies. In order to do so, the RP change can be approximated by a first order 2D Taylor expansion of equation 1 as a function of the changes in the mean and in the standard deviation of the GPP as follows:

(2) $R_{p_{-} s}=R_{p_{-} h}+\Delta R_{p}$,

where the $s$ stands for "scenario", the $h$ stands for "historical", and $\Delta$ represents the difference between two periods.

(3) $\Delta R_{p} \simeq \partial R / \partial \mu \cdot \Delta \mu+\partial R / \partial \sigma \cdot \Delta \sigma$

where $\partial$ is the partial derivative. By computing the derivatives and dividing both members of equation 3 by $R_{p}$ one obtains:

(4) $\Delta R_{p} / R_{p}=2 \Delta \mu / \mu-2 \Delta \sigma / \sigma$.

Thus, an indication on the changes induced by the mean and the variability on the resilience may be obtained by comparing the projected relative changes of the mean and of the variability, using the same weight. Equation 5 provides a normalized indicator of such comparison:

(5) $(|\Delta \mu / \mu|-|\Delta \sigma / \sigma|) /(|\Delta \mu / \mu|+|\Delta \sigma / \sigma|)$,

which varies from -1 (variability dominates) to +1 (mean dominates), which is useful to assess and compare the dominant relative changes in different locations.

\section{Results}

Future climate projections display significant changes of GPP variability resilience (Fig. 1) compared to period $1985-2014$. The annual vegetation primary production resilience indicator is anticipated to generally increase in the lower emission scenarios (ssp126 and ssp245, Fig. 1 a,b,c, and $d$, respectively). The larger positive changes are expected to occur especially in the snow dominated bioclimatic regions (see Table S2). The amplitude and the area covered by these changes are comparatively larger in the ssp245 scenario than in the ssp126 scenario and increase with time towards the end of the $21^{\text {st }}$ century (Table 2). Positive changes are also estimated for Central Africa and the Sahel regions, India and over the Himalayan Plateau. However, regions with loss of GPP resilience appear as well, especially in Brazil, China and surrounding countries of equatorial America. Under the ssp245 socio-economic scenario, the CMIP6 ESMs project resilience losses also in Mexico and the southern part of the US, the Mediterranean region, Southern Africa and Australia. This occurs not only in the far future (period 2051-2100, Fig. 1d), but also in the near future (period 2021-2050; Fig. 1c).

\section{- Figure 1 -}

Under the more moderate emission scenarios (ssp126 and ssp245), about one third of land area is going to experience an increase of vegetation annual GPP resilience over the period 2021-2050 (see Table 2). This proportion is slightly lower, about one forth, when considering only the areas where $75 \%$ of the models agree with the sign of changes. Differently, the area with positive changes will cover almost half of the global land area (less than one third when the constraint on models' agreement is introduced) over the period 2051-2100. Regions losing resilience cover a smaller 
percentage of the global area, about $10 \%$ under ssp245 in the near future period. The differences between the plain estimate and the one constrained on models' agreement become negligible for variations of resilience higher than $15 \%$ (Table 2).

The results for the ssp585 scenario stand out significantly compared to the lower emission scenarios. Broad areas with negative change (i.e. loss of vegetation GPP resilience) appear already in the period 2021-2050 (Fig. 1e) in the Amazon region, Unites States, South Canada, Western Europe, Mediterranean basin, as well as in the Middle east, Central, Western and Southern Africa, Southeast Asia and China, and Oceania. Areas with at least $5 \%$ loss of vegetation GPP resilience are projected to cover approximately one fifth of the global land $12 \%$ considering models' agreement); while areas with more than $15 \%$ losses are projected to be limited to $3 \%$. Positive gains of vegetation GPP resilience in boreal regions are simulated to be more limited with respect to the lower emission scenarios. Gains of at least $5 \%$ are expected to cover about one fourth of the global areas (15\% considering models' agreement); while areas with changes larger than $15 \%$ are limited to the $6 \%$, similarly to the ssp 126 scenario.

The severity of the projected losses is expected to further exacerbate in the period 2051-2100. In the 'Taking the Highway' scenario, less and less are the regions expected to experience gains in vegetation GPP resilience. These regions are: La Plata basin in Argentina, part of the Sahel region, Eastern Africa, Western India, North-western China and some regions along the coast of the Arctic Sea. In general, areas gaining at least $5 \%$ resilience are simulated to be limited to $14 \%(8 \%$ considering model agreement) of global areas, while regions with more than $15 \%$ increase of vegetation primary production resilience are limited globally to $6 \%$ of the land area. The areas losing resilience are expected to outbalance those ones increasing resilience and cover $43 \%$ (25\% considering models agreement) of global land area with more than $5 \%$ resilience losses. Globally, $13 \%$ of land areas are predicted to lose more than $15 \%$ vegetation primary production resilience.

\section{- Figure 2 -}

The GPP resilience changes can be driven either by the change in the GPP mean and by the changes in the GPP variability due to climate change (see Methods). Positive resilience changes in the near future under moderate emission scenarios are often linked to positive changes in the mean annual GPP (Fig. 2a,b,c,d,e, S4) connected to overall higher levels of atmospheric $\mathrm{CO}_{2}$ concentration and to higher mean growing temperature in Boreal Regions. Negative resilience changes are generally associated to an increase of interannual variability of GPP (see Fig. S5). The areas affected by an increase of variability largely change across the scenarios and reach their maximum extent under the scenario ssp585 (Fig. 2e,f, S5e,f).

- Figure 3 -

Gain and losses of resilience are quantified at the national level in order to provide country-specific information for adaptation options, and possibly to support ambitious mitigation policies. This analysis is displayed in Figure 3 for the ten largest countries (and in Table S3 for all World countries). Russia is characterized by the widest gains of resilience, which could cover almost $70 \%$ of the country area in the period 2051-2100 under the ssp245 scenario. The spatial extent of areas expected to experience gains is reduced up to about 15\% in the near future under the ssp585 scenario. This tendency continues towards the end of the century, under the ssp585 scenario, when also areas with GPP resilience losses start to appear. Canada shows a similar picture, but with less optimistic estimation of predicted losses largely outbalancing the gains in the 2051-2100 period under the ssp585 scenario. The USA and China display similar figures, with gains predicted to reach $20 \%$ in the low emission scenarios (ssp126 and ssp245) and losses ranging from 10\% to $15 \%$ in the ssp585 over the period 2051-2100. Among the largest countries, Brazil is the one characterized by the worst projections, with the risk of losing resilience in $50 \%$ of its total territory under the ssp585 scenario at the end of the $21^{\text {st }}$ Century. It is worth noting that these changes are likely to represent an underestimation as the current trend of land-use change (Freitas et al., 2018) 
is only partially considered in the ESMs (Hurtt et al., 2020). Australia is estimated to undergo negligible losses, also because over desert and arid areas resilience changes are proportionally small. Nevertheless, Australia will experience comparatively large losses of resilience towards the end of the century under the ssp585 scenario. The European Union is characterized by a more stable situation with significant positive changes only under the ssp245 scenario over the period 2051-2100. India shows projections similar to the EU, but with significant areas of vegetation that both gain and lose resilience under the high emission scenario at the end of the $21^{\text {st }}$ Century. Large positive and negative changes in resilience are also estimated for Argentina under the high emission scenario (2051-2100). Whether or not these compensating changes in different area are beneficial for the countries' adaptive capacity could be subject of specific follow-up investigations.

Results for the remaining World countries (see Table S3) allow identifying severe cases, such as losses of resilience higher than $15 \%$ over more than $50 \%$ of the area under the ssp585 scenario over the period 2051-2100 in Gabon, Bhutan, Venezuela, Equatorial Guinea, Malaysia, Peru, Guyana, Lebanon, Japan, Congo, Bolivia, Honduras, Zambia, South Korea, Papua Nuova Guinea and other 16 countries. Under the same scenario, the list of 'winner' countries is much shorter, with only Somalia gaining at least $15 \%$ resilience over more than $50 \%$ of its territory. Countries having the largest benefit under the ssp245 scenario at the end of the century are Russia and the ones in Northern Europe. Under the ssp126 scenario, the benefits are geographically spread into more continents. In both ssp126 and ssp245 scenarios, there are almost no countries experiencing more than $15 \%$ losses of resilience over $10 \%$ of their land.

\section{Discussion and Conclusions}

This study explores the linkages between future changes in resilience of global vegetation gross primary production (GPP) and the mitigation pathways that society can undertake to conserve and restore ecosystems and their services, on which human well-being depends. The analysis presented here highlights the world regions where there might be losses of vegetation GPP resilience as well as the countries that are subject to the most urgent necessity of improving adaptive capacity and resilience to climate-related hazards under different future climate scenarios.

The results of our analysis strongly support the SDG-13 on taking action to combat climate change and its impacts. Over anthropized area, our results are relevant for agricultural production, which is a main source of employment, livelihood and income for a large portion of population especially in developing countries (SDG-1, no poverty) as well as a main food source (SDG-2, no hunger). Our results are also relevant for the SDG-15, on the sustainable management of ecosystems and halting land degradation and biodiversity loss. Recent studies have looked at the resistance and resilience of global vegetation to short-term climate anomalies (De Keersmaecker et al., 2017) and ecosystem stability to droughts events (Huang and Xia, 2019; Ivits et al., 2012), and have highlighted how the diversity of vegetation composition and biodiversity enhances ecosystem stability (Geng et al., 2019) and the resilience of ecosystem productivity to climate extremes (Isbell et al., 2015). Enhancing biodiversity and natural capital in the most threatened areas we identified is a necessary action for the conservation and restoration of ecosystems and their services as well as to increase their stability, resilience and productivity (Cardinale et al., 2012; IPBES, 2018; Isbell et al., 2015).

The presented analysis adopts a recently proposed quantitative measure of resilience for agricultural (Zampieri et al., 2020c) and natural vegetation (Zampieri et al., 2019) productivity in order to diagnose future changes in the resilience of vegetation GPP) as represented by a large ensemble of Earth System Models simulations included in the Sixth Coupled Model Intercomparison Project (CMIP6) of the Intergovernmental Panel on Climate Change (IPCC). 
Our results show large differences in the changes of GPP resilience across the globe, depending on greenhouse gases concentration of the projected scenarios. Under low emission scenarios, as found in previous studies (Hubau et al., 2020), the $\mathrm{CO}_{2}$ fertilization effect often prevail over the negative effect due global warming and to the increase of climate variability. Our results are in general agreement with the observed changes in vegetation distribution that are already observed especially in boreal regions (Keeling et al., 1996; Myneni et al., 1997). This tendency is expected to increase in the future climate scenarios, especially those with higher greenhouse gases and radiative forcing increases (Madani et al., 2018; Zampieri and Lionello, 2010; Zhang et al., 2017). However, radiation will always be a limiting factor for the vegetation adaptation at very high latitudes (Bjorkman et al., 2017; Seddon et al., 2016).

The main findings point to areas in the mid-latitudes where vegetation resilience is estimated to decrease in the higher emission scenarios, such as the Mediterranean, the mid-West in the US, Central America, part of China, Southern Africa and Australia. This tendency might compromise the stability of agricultural production and the reliability of ecosystem services provided by the natural vegetation in these regions, unless sensible adaptation actions are taken. The relevance of mitigation is most evident under the higher emission scenarios, where vegetation resilience is affected in most land areas and especially in tropical regions, where society is highly dependent on ecosystem services and more vulnerable to climatic changes.

Overall, in the scenario with lower mitigation, the areas losing vegetation resilience are more than the ones gaining resilience, jeopardizing the stability of the ecosystems structure (and of the related services). Adapting to changes in variability more than to changes in the mean production of vegetation will be critical for society and natural ecosystems in areas experiencing vegetation GPP resilience losses.

In comparison to other stability and resilience metrics, the approach adopted here offers some advantages. First of all, the annual production resilience indicator is consistent with the ecological definition of resilience by Holling (1973) because the particular combination of the mean and the variance defining it is proportional to the return period of the largest disturbance that an homogeneous system can absorb before losing the annual production (Zampieri et al., 2020c). In case the production is diversified, or the system is spatially inhomogeneous, the annual production resilience indicator increases with diversity. In particular, it increases linearly with the number of species, if their production time-series are uncorrelated among each other. In addition, if a constant portion of the area where the vegetation is computed is base ground (zero productivity), the indicator automatically adjust itself to estimate the resilience of the vegetated fraction (Zampieri et al., 2019). If the system is characterized by recovery timings larger than one year (a growing season), the value of the indicator decreases, as expected (Zampieri et al., 2020c).

However, the annual production resilience indicator has also some limitations. It does not point to the drivers determining resilience of GPP and its changes and requires relatively long data time series (see Methods and Appendix A). On the first aspect, as shown in this study, distinguishing between changes in the mean and in the variability of GPP, which are two components of the indicators, can provide additional information on the patterns behind changes. On the second aspect, using remote-sensing data, as suggested also in other large-scale studies on ecosystem stability (White et al., 2020), or long-term multi-model simulations' ensembles such as the one analysed here are favourable contexts of application.

\section{Acknowledgments}

For transparency and reproducibility, this paper uses publicly available data provided by the IPCC through the Earth System Grid Federation LLNL, CEDA, DKRZ, GFDL, IPSL, LIU, NCI and NCCS 
nodes (ESGF, https://esgf.Ilnl.gov/nodes.html) and open-source software to compute the annual production resilience indicator (Zampieri et al., 2020).

Author Contributions: $M Z$ conceived the study and drafted the paper, $M Z$ and $B G$ performed the analysis, PDP downloaded data and performed initial checking, all authors reviewed the manuscript and contributed to the final version.

\section{References}

Arora, V.K., Scinocca, J.F., 2016. Constraining the strength of the terrestrial CO $\$ \_\{2\} \$$ fertilization effect in the Canadian Earth system model version 4.2 (CanESM4.2). Geosci. Model Dev. 9, 2357-2376. https://doi.org/10.5194/gmd-9-2357-2016

Bastos, A., O'Sullivan, M., Ciais, P., Makowski, D., Sitch, S., Friedlingstein, P., Chevallier, F., Rödenbeck, C., Pongratz, J., Luijkx, I.T., Patra, P.K., Peylin, P., Canadell, J.G., Lauerwald, R., Li, W., Smith, N.E., Peters, W., Goll, D.S., Jain, A.K., Kato, E., Lienert, S., Lombardozzi, D.L., Haverd, V., Nabel, J.E.M.S., Poulter, B., Tian, H., Walker, A.P., Zaehle, S., 2020. Sources of Uncertainty in Regional and Global Terrestrial CO2 Exchange Estimates. Global Biogeochem. Cycles 34, e2019GB006393. https://doi.org/10.1029/2019GB006393

Betts, R.A., Alfieri, L., Bradshaw, C., Caesar, J., Feyen, L., Friedlingstein, P., Gohar, L., Koutroulis, A., Lewis, K., Morfopoulos, C., Papadimitriou, L., Richardson, K.J., Tsanis, I., Wyser, K., 2018. Changes in climate extremes, fresh water availability and vulnerability to food insecurity projected at $1.5^{\circ} \mathrm{C}$ and $2^{\circ} \mathrm{C}$ global warming with a higher-resolution global climate model. Philos. Trans. R. Soc. A Math. Phys. Eng. Sci. 376, 20160452. https://doi.org/10.1098/rsta.2016.0452

Bjorkman, A.D., Vellend, M., Frei, E.R., Henry, G.H.R., 2017. Climate adaptation is not enough: warming does not facilitate success of southern tundra plant populations in the high Arctic. Glob. Chang. Biol. 23, 1540-1551. https://doi.org/https://doi.org/10.1111/gcb.13417

Bonan, G.B., 1998. The Land Surface Climatology of the NCAR Land Surface Model Coupled to the NCAR Community Climate Model*. J. Clim. 11, 1307-1326. https://doi.org/10.1175/1520-0442(1998)011<1307:TLSCOT>2.0.CO;2

Cardinale, B.J., Duffy, J.E., Gonzalez, A., Hooper, D.U., Perrings, C., Venail, P., Narwani, A., Mace, G.M., Tilman, D., Wardle, D.A., Kinzig, A.P., Daily, G.C., Loreau, M., Grace, J.B., Larigauderie, A., Srivastava, D.S., Naeem, S., 2012. Biodiversity loss and its impact on humanity. Nature 486, 59-67. https://doi.org/10.1038/nature11148

Chen, C., He, B., Yuan, W., Guo, L., Zhang, Y., 2019. Increasing interannual variability of global vegetation greenness. Environ. Res. Lett. 14, 124005. https://doi.org/10.1088/17489326/ab4ffc

Chen, Y., Ryder, J., Bastrikov, V., McGrath, M.J., Naudts, K., Otto, J., Ottlé, C., Peylin, P., Polcher, J., Valade, A., Black, A., Elbers, J.A., Moors, E., Foken, T., van Gorsel, E., Haverd, V., Heinesch, B., Tiedemann, F., Knohl, A., Launiainen, S., Loustau, D., Ogée, J., Vessala, T., Luyssaert, S., 2016. Evaluating the performance of land surface model ORCHIDEECAN v1.0 on water and energy flux estimation with a single- and multi-layer energy budget scheme. Geosci. Model Dev. 9, 2951-2972. https://doi.org/10.5194/gmd-9-2951-2016

Ciais, P., Reichstein, M., Viovy, N., Granier, A., Ogée, J., Allard, V., Aubinet, M., Buchmann, N., 
Bernhofer, C., Carrara, A., Chevallier, F., De Noblet, N., Friend, A.D., Friedlingstein, P., Grünwald, T., Heinesch, B., Keronen, P., Knohl, A., Krinner, G., Loustau, D., Manca, G., Matteucci, G., Miglietta, F., Ourcival, J.M., Papale, D., Pilegaard, K., Rambal, S., Seufert, G., Soussana, J.F., Sanz, M.J., Schulze, E.D., Vesala, T., Valentini, R., 2005. Europe-wide reduction in primary productivity caused by the heat and drought in 2003 . Nature 437, 529533. https://doi.org/10.1038/nature03972

Costanza, R., de Groot, R., Sutton, P., van der Ploeg, S., Anderson, S.J., Kubiszewski, I., Farber, S., Turner, R.K., 2014. Changes in the global value of ecosystem services. Glob. Environ. Chang. 26, 152-158. https://doi.org/https://doi.org/10.1016/j.gloenvcha.2014.04.002

Dahan, A., 2010. Putting the Earth System in a numerical box? The evolution from climate modeling toward global change. Stud. Hist. Philos. Sci. Part B Stud. Hist. Philos. Mod. Phys. 41, 282-292. https://doi.org/https://doi.org/10.1016/j.shpsb.2010.08.002

Dakos, V., Carpenter, S.R., Brock, W.A., Ellison, A.M., Guttal, V., Ives, A.R., Kéfi, S., Livina, V., Seekell, D.A., van Nes, E.H., Scheffer, M., 2012. Methods for Detecting Early Warnings of Critical Transitions in Time Series Illustrated Using Simulated Ecological Data. PLoS One 7, e41010.

Dass, P., Rawlins, M.A., Kimball, J.S., Kim, Y., 2016. Environmental controls on the increasing GPP of terrestrial vegetation across northern Eurasia. Biogeosciences 13, 45-62. https://doi.org/10.5194/bg-13-45-2016

De Kauwe, M.G., Kala, J., Lin, Y.-S., Pitman, A.J., Medlyn, B.E., Duursma, R.A., Abramowitz, G., Wang, Y.-P., Miralles, D.G., 2015. A test of an optimal stomatal conductance scheme within the CABLE land surface model. Geosci. Model Dev. 8, 431-452. https://doi.org/10.5194/gmd-8-431-2015

De Keersmaecker, W., Lhermitte, S., Hill, M.J., Tits, L., Coppin, P., Somers, B., 2017. Assessment of Regional Vegetation Response to Climate Anomalies: A Case Study for Australia Using GIMMS NDVI Time Series between 1982 and 2006. Remote Sens. 9. https://doi.org/10.3390/rs9010034

De Keersmaecker, W., Lhermitte, S., Honnay, O., Farifteh, J., Somers, B., Coppin, P., 2014a. How to measure ecosystem stability? An evaluation of the reliability of stability metrics based on remote sensing time series across the major global ecosystems. Glob. Chang. Biol. 20, 2149-2161. https://doi.org/10.1111/gcb.12495

De Keersmaecker, W., Lhermitte, S., Honnay, O., Farifteh, J., Somers, B., Coppin, P., 2014b. How to measure ecosystem stability? An evaluation of the reliability of stability metrics based on remote sensing time series across the major global ecosystems. Glob. Chang. Biol. 20, 2149-2161. https://doi.org/10.1111/gcb.12495

Dickinson, R.E., Shaikh, M., Bryant, R., Graumlich, L., 1998. Interactive Canopies for a Climate Model. J. Clim. 11, 2823-2836. https://doi.org/10.1175/1520-

0442(1998)011<2823:ICFACM>2.0.CO;2

Dosio, A., Mentaschi, L., Fischer, E.M., Wyser, K., 2018. Extreme heat waves under 1.5 and 2 degree global warming(Supplementary data). Environ. Res. L 1-9.

Fibbi, L., Moriondo, M., Chiesi, M., Bindi, M., Maselli, F., 2019. Impacts of climate change on the gross primary production of Italian forests. Ann. For. Sci. 76, 59.

https://doi.org/10.1007/s13595-019-0843-x 
Forrest, M., Tost, H., Lelieveld, J., Hickler, T., 2018. Towards an advanced atmospheric chemistry-enabled ESM with dynamic land surface processes: Part I - Linking LPJ-GUESS (v4.0) with EMAC modelling system (v2.53). Geosci. Model Dev. Discuss. 2018, 1-21. https://doi.org/10.5194/gmd-2018-135

Freitas, F.L.M., Sparovek, G., Berndes, G., Persson, U.M., Englund, O., Barretto, A., Mörtberg, U., 2018. Potential increase of legal deforestation in Brazilian Amazon after Forest Act revision. Nat. Sustain. 1, 665-670. https://doi.org/10.1038/s41893-018-0171-4

Garrigues, S., Olioso, A., Calvet, J.C., Martin, E., Lafont, S., Moulin, S., Chanzy, A., Marloie, O., Buis, S., Desfonds, V., Bertrand, N., Renard, D., 2015a. Evaluation of land surface model simulations of evapotranspiration over a 12-year crop succession: impact of soil hydraulic and vegetation properties. Hydrol. Earth Syst. Sci. 19, 3109-3131. https://doi.org/10.5194/hess-19-3109-2015

Garrigues, S., Olioso, A., Carrer, D., Decharme, B., Calvet, J.-C., Martin, E., Moulin, S., Marloie, O., 2015b. Impact of climate, vegetation, soil and crop management variables on multi-year ISBA-A-gs simulations of evapotranspiration over a Mediterranean crop site. Geosci. Model Dev. 8, 3033-3053. https://doi.org/10.5194/gmd-8-3033-2015

Geng, S., Shi, P., Song, M., Zong, N., Zu, J., Zhu, W., 2019. Diversity of vegetation composition enhances ecosystem stability along elevational gradients in the Taihang Mountains, China. Ecol. Indic. 104, 594-603. https://doi.org/10.1016/j.ecolind.2019.05.038

Gerber, S., Hedin, L.O., Oppenheimer, M., Pacala, S.W., Shevliakova, E., 2010. Nitrogen cycling and feedbacks in a global dynamic land model. Global Biogeochem. Cycles 24. https://doi.org/10.1029/2008GB003336

Harper, A.B., Cox, P.M., Friedlingstein, P., Wiltshire, A.J., Jones, C.D., Sitch, S., Mercado, L.M., Groenendijk, M., Robertson, E., Kattge, J., Bönisch, G., Atkin, O.K., Bahn, M., Cornelissen, J., Niinemets, Ü., Onipchenko, V., Peñuelas, J., Poorter, L., Reich, P.B., Soudzilovskaia, N.A., Bodegom, P. V, 2016. Improved representation of plant functional types and physiology in the Joint UK Land Environment Simulator (JULES v4.2) using plant trait information. Geosci. Model Dev. 9, 2415-2440. https://doi.org/10.5194/gmd-9-2415-2016

Holling, C.S., 1996. Engineering Resilience versus Ecological Resilience. The National Academy of Sciences.

Holling, C.S., 1973. Resilience and stability of ecological systems. Annu. Rev. Ecol. Syst. 4, 123.

Huang, K., Xia, J., 2019. High ecosystem stability of evergreen broadleaf forests under severe droughts. Glob. Chang. Biol. 25, 3494-3503.

https://doi.org/https://doi.org/10.1111/gcb.14748

Huang, Y., Gerber, S., Huang, T., Lichstein, J.W., 2016. Evaluating the drought response of CMIP5 models using global gross primary productivity, leaf area, precipitation, and soil moisture data. Global Biogeochem. Cycles 30, 1827-1846.

https://doi.org/https://doi.org/10.1002/2016GB005480

Hubau, W., Lewis, S.L., Phillips, O.L., Affum-Baffoe, K., Beeckman, H., Cuní-Sanchez, A., Daniels, A.K., Ewango, C.E.N., Fauset, S., Mukinzi, J.M., Sheil, D., Sonké, B., Sullivan, M.J.P., Sunderland, T.C.H., Taedoumg, H., Thomas, S.C., White, L.J.T., Abernethy, K.A., Adu-Bredu, S., Amani, C.A., Baker, T.R., Banin, L.F., Baya, F., Begne, S.K., Bennett, A.C., 
Benedet, F., Bitariho, R., Bocko, Y.E., Boeckx, P., Boundja, P., Brienen, R.J.W., Brncic, T., Chezeaux, E., Chuyong, G.B., Clark, C.J., Collins, M., Comiskey, J.A., Coomes, D.A., Dargie, G.C., de Haulleville, T., Kamdem, M.N.D., Doucet, J.-L., Esquivel-Muelbert, A., Feldpausch, T.R., Fofanah, A., Foli, E.G., Gilpin, M., Gloor, E., Gonmadje, C., GourletFleury, S., Hall, J.S., Hamilton, A.C., Harris, D.J., Hart, T.B., Hockemba, M.B.N., Hladik, A., Ifo, S.A., Jeffery, K.J., Jucker, T., Yakusu, E.K., Kearsley, E., Kenfack, D., Koch, A., Leal, M.E., Levesley, A., Lindsell, J.A., Lisingo, J., Lopez-Gonzalez, G., Lovett, J.C., Makana, J.R., Malhi, Y., Marshall, A.R., Martin, J., Martin, E.H., Mbayu, F.M., Medjibe, V.P., Mihindou, V., Mitchard, E.T.A., Moore, S., Munishi, P.K.T., Bengone, N.N., Ojo, L., Ondo, F.E., Peh, K.S.-H., Pickavance, G.C., Poulsen, A.D., Poulsen, J.R., Qie, L., Reitsma, J., Rovero, F., Swaine, M.D., Talbot, J., Taplin, J., Taylor, D.M., Thomas, D.W., Toirambe, B., Mukendi, J.T., Tuagben, D., Umunay, P.M., van der Heijden, G.M.F., Verbeeck, H., Vleminckx, J., Willcock, S., Wöll, H., Woods, J.T., Zemagho, L., 2020. Asynchronous carbon sink saturation in African and Amazonian tropical forests. Nature 579, 80-87. https://doi.org/10.1038/s41586-020-2035-0

Hurtt, G.C., Chini, L., Sahajpal, R., Frolking, S., Bodirsky, B.L., Calvin, K., Doelman, J.C., Fisk, J., Fujimori, S., Goldewijk, K.K., Hasegawa, T., Havlik, P., Heinimann, A., Humpenöder, F., Jungclaus, J., Kaplan, J., Kennedy, J., Kristzin, T., Lawrence, D., Lawrence, P., Ma, L., Mertz, O., Pongratz, J., Popp, A., Poulter, B., Riahi, K., Shevliakova, E., Stehfest, E., Thornton, P., Tubiello, F.N., van Vuuren, D.P., Zhang, X., 2020. Harmonization of Global Land-Use Change and Management for the Period 850--2100 (LUH2) for CMIP6. Geosci. Model Dev. Discuss. 2020, 1-65. https://doi.org/10.5194/gmd-2019-360

IPBES, 2018. The IPBES assessment report on land degradation and restoration. Secretariat of the Intergovernmental Science-Policy Platform on Biodiversity and Ecosystem Services, Bonn, Germany.

Isbell, F., Craven, D., Connolly, J., Loreau, M., Schmid, B., Beierkuhnlein, C., Bezemer, T.M., Bonin, C., Bruelheide, H., de Luca, E., Ebeling, A., Griffin, J.N., Guo, Q., Hautier, Y., Hector, A., Jentsch, A., Kreyling, J., Lanta, V., Manning, P., Meyer, S.T., Mori, A.S., Naeem, S., Niklaus, P.A., Polley, H.W., Reich, P.B., Roscher, C., Seabloom, E.W., Smith, M.D., Thakur, M.P., Tilman, D., Tracy, B.F., van der Putten, W.H., van Ruijven, J., Weigelt, A., Weisser, W.W., Wilsey, B., Eisenhauer, N., 2015. Biodiversity increases the resistance of ecosystem productivity to climate extremes. Nature 526, 574-577. https://doi.org/10.1038/nature15374

Ito, A., Inatomi, M., 2011. Water-Use Efficiency of the Terrestrial Biosphere: A Model Analysis Focusing on Interactions between the Global Carbon and Water Cycles. J. Hydrometeorol. 13, 681-694. https://doi.org/10.1175/JHM-D-10-05034.1

Ivits, E., Cherlet, M., Tóth, G., Sommer, S., Mehl, W., Vogt, J., Micale, F., 2012. Combining satellite derived phenology with climate data for climate change impact assessment. Glob. Planet. Change 88-89, 85-97. https://doi.org/https://doi.org/10.1016/j.gloplacha.2012.03.010

Johnstone, J.F., Allen, C.D., Franklin, J.F., Frelich, L.E., Harvey, B.J., Higuera, P.E., Mack, M.C., Meentemeyer, R.K., Metz, M.R., Perry, G.L.W., Schoennagel, T., Turner, M.G., 2016. Changing disturbance regimes, ecological memory, and forest resilience. Front. Ecol. Environ. 14, 369-378. https://doi.org/https://doi.org/10.1002/fee.1311

Jones, P.W., 1999. First- and Second-Order Conservative Remapping Schemes for Grids in Spherical Coordinates. Mon. Weather Rev. 127, 2204-2210. https://doi.org/10.1175/15200493(1999)127<2204:FASOCR>2.0.CO;2 
Keeling, C.D., Chin, J.F.S., Whorf, T.P., 1996. Increased activity of northern vegetation inferred from atmospheric CO2 measurements. Nature 382, 146-149.

https://doi.org/10.1038/382146a0

Kimball, J.S., Zhao, M., McGuire, A.D., Heinsch, F.A., Clein, J., Calef, M., Jolly, W.M., Kang, S., Euskirchen, S.E., McDonald, K.C., Running, S.W., 2009. Recent Climate-Driven Increases in Vegetation Productivity for the Western Arctic: Evidence of an Acceleration of the Northern Terrestrial Carbon Cycle. Earth Interact. 11, 1-30. https://doi.org/10.1175/El180.1

Knauer, J., Werner, C., Zaehle, S., 2015. Evaluating stomatal models and their atmospheric drought response in a land surface scheme: A multibiome analysis. J. Geophys. Res. Biogeosciences 120, 1894-1911. https://doi.org/https://doi.org/10.1002/2015JG003114

Koven, C.D., Riley, W.J., Subin, Z.M., Tang, J.Y., Torn, M.S., Collins, W.D., Bonan, G.B., Lawrence, D.M., Swenson, S.C., 2013. The effect of vertically resolved soil biogeochemistry and alternate soil $\mathrm{C}$ and $\mathrm{N}$ models on $\mathrm{C}$ dynamics of CLM4. Biogeosciences 10, 71097131. https://doi.org/10.5194/bg-10-7109-2013

Lawrence, D.M., Fisher, R.A., Koven, C.D., Oleson, K.W., Swenson, S.C., Bonan, G., Collier, N., Ghimire, B., van Kampenhout, L., Kennedy, D., Kluzek, E., Lawrence, P.J., Li, F., Li, H., Lombardozzi, D., Riley, W.J., Sacks, W.J., Shi, M., Vertenstein, M., Wieder, W.R., Xu, C., Ali, A.A., Badger, A.M., Bisht, G., van den Broeke, M., Brunke, M.A., Burns, S.P., Buzan, J., Clark, M., Craig, A., Dahlin, K., Drewniak, B., Fisher, J.B., Flanner, M., Fox, A.M., Gentine, P., Hoffman, F., Keppel-Aleks, G., Knox, R., Kumar, S., Lenaerts, J., Leung, L.R., Lipscomb, W.H., Lu, Y., Pandey, A., Pelletier, J.D., Perket, J., Randerson, J.T., Ricciuto, D.M., Sanderson, B.M., Slater, A., Subin, Z.M., Tang, J., Thomas, R.Q., Val Martin, M., Zeng, X., 2019. The Community Land Model Version 5: Description of New Features, Benchmarking, and Impact of Forcing Uncertainty. J. Adv. Model. Earth Syst. 11, 4245-4287. https://doi.org/10.1029/2018MS001583

Liu, L., Zhang, Y., Wu, S., Li, S., Qin, D., 2018. Water memory effects and their impacts on global vegetation productivity and resilience. Sci. Rep. 8, 2962. https://doi.org/10.1038/s41598018-21339-4

Lloret, F., Lobo, A., Estevan, H., Maisongrande, P., Vayreda, J., Terradas, J., 2007. Woody Plant Richness and NDVI Response to Drought Events in Catalonian (Northeastern Spain) Forests. Ecology 88, 2270-2279.

Lotka, A.J., 1920. Analytical Note on Certain Rhythmic Relations in Organic Systems. Proc. Natl. Acad. Sci. 6, 410-415. https://doi.org/10.1073/pnas.6.7.410

Loveland, T.R., Belward, A.S., 1997. The IGBP-DIS global $1 \mathrm{~km}$ land cover data set, DISCover: First results. Int. J. Remote Sens. 18, 3289-3295. https://doi.org/10.1080/014311697217099

Madani, N., Kimball, J.S., Ballantyne, A.P., Affleck, D.L.R., van Bodegom, P.M., Reich, P.B., Kattge, J., Sala, A., Nazeri, M., Jones, M.O., Zhao, M., Running, S.W., 2018. Future global productivity will be affected by plant trait response to climate. Sci. Rep. 8, 2870. https://doi.org/10.1038/s41598-018-21172-9

MAE, 2005. Millennium Ecosystem Assessment. Ecosystems and Human Well-Being: Synthesis. Washington DC.

Meyer, K., 2016. A mathematical rewiew of resilience in ecology. Nat. Resour. Model. 29, 339- 
352. https://doi.org/10.1111/nrm.12097

Mitchell, J.F.B., Johns, T.C., Gregory, J.M., Tett, S.F.B., 1995. Climate response to increasing levels of greenhouse gases and sulphate aerosols. Nature 376, 501-504.

https://doi.org/10.1038/376501a0

Moore, J.C., de Ruiter, P.C., Hunt, H.W., 1993. Influence of Productivity on the Stability of Real and Model Ecosystems. Science (80-. ). 261, 906-908.

https://doi.org/10.1126/science.261.5123.906

Morecroft, M.D., Crick, H.Q.P., Duffield, S.J., Macgregor, N.A., 2012. Resilience to climate change: translating principles into practice. J. Appl. Ecol. 49, 547-551.

https://doi.org/10.1111/j.1365-2664.2012.02136.x

Murphy, J.M., 1995. Transient Response of the Hadley Centre Coupled Ocean-Atmosphere Model to Increasing Carbon Dioxide. Part III: Analysis of Global-Mean Response Using Simple Models. J. Clim. 8, 496-514. https://doi.org/10.1175/15200442(1995)008<0496:TROTHC>2.0.CO;2

Myneni, R.B., Keeling, C.D., Tucker, C.J., Asrar, G., Nemani, R.R., 1997. Increased plant growth in the northern high latitudes from 1981 to 1991 . Nature 386, 698-702. https://doi.org/10.1038/386698a0

Naumann, G., Alfieri, L., Wyser, K., Mentaschi, L., Betts, R.A., Carrao, H., Spinoni, J., Vogt, J., Feyen, L., 2018. Global Changes in Drought Conditions under Different Levels of Warming. Geophys. Res. Lett. https://doi.org/10.1002/2017GL076521

Ogle, K., Barber, J.J., Barron-Gafford, G.A., Bentley, L.P., Young, J.M., Huxman, T.E., Loik, M.E., Tissue, D.T., 2015. Quantifying ecological memory in plant and ecosystem processes. Ecol. Lett. 18, 221-235. https://doi.org/https://doi.org/10.1111/ele.12399

Oliver, T.H., Heard, M.S., Isaac, N.J.B., Roy, D.B., Procter, D., Eigenbrod, F., Freckleton, R., Hector, A., Orme, C.D.L., Petchey, O.L., Proença, V., Raffaelli, D., Suttle, K.B., Mace, G.M., Martín-López, B., Woodcock, B.A., Bullock, J.M., 2015. Biodiversity and Resilience of Ecosystem Functions. Trends Ecol. Evol. 30, 673-684. https://doi.org/https://doi.org/10.1016/j.tree.2015.08.009

Orth, R., Destouni, G., Jung, M., Reichstein, M., 2020. Large-scale biospheric drought response intensifies linearly with drought duration in arid regions. Biogeosciences 17, 2647-2656. https://doi.org/10.5194/bg-17-2647-2020

Peano, D., Materia, S., Collalti, A., Alessandri, A., Anav, A., Bombelli, A., Gualdi, S., 2019. Global Variability of Simulated and Observed Vegetation Growing Season. J. Geophys. Res. Biogeosciences 124, 3569-3587. https://doi.org/10.1029/2018JG004881

Peng, C. -K., Havlin, S., Stanley, H.E., Goldberger, A.L., 1995. Quantification of scaling exponents and crossover phenomena in nonstationary heartbeat time series. Chaos An Interdiscip. J. Nonlinear Sci. 5, 82-87. https://doi.org/10.1063/1.166141

Peters, W., van der Velde, I.R., van Schaik, E., Miller, J.B., Ciais, P., Duarte, H.F., van der LaanLuijkx, I.T., van der Molen, M.K., Scholze, M., Schaefer, K., Vidale, P.L., Verhoef, A., Wårlind, D., Zhu, D., Tans, P.P., Vaughn, B., White, J.W.C., 2018. Increased water-use efficiency and reduced $\mathrm{CO}(2)$ uptake by plants during droughts at a continental-scale. Nat. Geosci. 11, 744-748. https://doi.org/10.1038/s41561-018-0212-7 
Pimm, S.L., 1984. The complexity and stability of ecosystems. Nature 307, 321-326. https://doi.org/10.1038/307321a0

Pokhrel, Y., Felfelani, F., Satoh, Y., Boulange, J., Burek, P., Gädeke, A., Gerten, D., Gosling, S.N., Grillakis, M., Gudmundsson, L., Hanasaki, N., Kim, H., Koutroulis, A., Liu, J., Papadimitriou, L., Schewe, J., Müller Schmied, H., Stacke, T., Telteu, C.-E., Thiery, W., Veldkamp, T., Zhao, F., Wada, Y., 2021. Global terrestrial water storage and drought severity under climate change. Nat. Clim. Chang. https://doi.org/10.1038/s41558-02000972-w

Quinlan, A.E., Berbés-Blázquez, M., Haider, L.J., Peterson, G.D., 2016. Measuring and assessing resilience: broadening understanding through multiple disciplinary perspectives. J. Appl. Ecol. 53, 677-687. https://doi.org/10.1111/1365-2664.12550

Randall, D.A., Bitz, C.M., Danabasoglu, G., Denning, A.S., Gent, P.R., Gettelman, A., Griffies, S.M., Lynch, P., Morrison, H., Pincus, R., Thuburn, J., 2019. 100 Years of Earth System Model Development. Meteorol. Monogr. 59, 12.1-12.66. https://doi.org/10.1175/AMSMONOGRAPHS-D-18-0018.1

Raupach, M.R., Marland, G., Ciais, P., Le Quéré, C., Canadell, J.G., Klepper, G., Field, C.B., 2007. Global and regional drivers of accelerating CO2 emissions. Proc. Natl. Acad. Sci. 104, 10288-10293. https://doi.org/10.1073/pnas.0700609104

Reick, C.H., Raddatz, T., Brovkin, V., Gayler, V., 2013. Representation of natural and anthropogenic land cover change in MPI-ESM. J. Adv. Model. Earth Syst. 5, 459-482. https://doi.org/10.1002/jame.20022

Richmond, A., Kaufmann, R.K., Myneni, R.B., 2007. Valuing ecosystem services: A shadow price for net primary production. Ecol. Econ. 64, 454-462. https://doi.org/https://doi.org/10.1016/j.ecolecon.2007.03.009

Riley, W.J., Subin, Z.M., Lawrence, D.M., Swenson, S.C., Torn, M.S., Meng, L., Mahowald, N.M., Hess, P., 2011. Barriers to predicting changes in global terrestrial methane fluxes: analyses using CLM4Me, a methane biogeochemistry model integrated in CESM. Biogeosciences 8, 1925-1953. https://doi.org/10.5194/bg-8-1925-2011

Sage, R.F., Kubian, D.S., 2007. The temperature response of C3 and C4 photosynthesis. Plant. Cell Environ. 30, 1086-1106. https://doi.org/10.1111/j.1365-3040.2007.01682.x

Sausen, R., Barthel, K., Hasselmann, K., 1988. Coupled ocean-atmosphere models with flux correction. Clim. Dyn. 2, 145-163. https://doi.org/10.1007/BF01053472

Scheffer, M., Carpenter, S.R., Dakos, V., van Nes, E.H., 2015. Generic Indicators of Ecological Resilience: Inferring the Chance of a Critical Transition. Annu. Rev. Ecol. Evol. Syst. 46, 145-167. https://doi.org/10.1146/annurev-ecolsys-112414-054242

Seddon, A.W.R., Macias-Fauria, M., Long, P.R., Benz, D., Willis, K.J., 2016. Sensitivity of global terrestrial ecosystems to climate variability. Nature 531, 229.

Seddon, N., Turner, B., Berry, P., Chausson, A., Girardin, C.A.J., 2019. Grounding nature-based climate solutions in sound biodiversity science. Nat. Clim. Chang. 9, 84-87. https://doi.org/10.1038/s41558-019-0405-0

Seneviratne, S.I., Corti, T., Davin, E.L., Hirschi, M., Jaeger, E.B., Lehner, I., Orlowsky, B., 
Teuling, A.J., 2010. Investigating soil moisture-climate interactions in a changing climate: A review. Earth-Science Rev. 99, 125-161.

https://doi.org/https://doi.org/10.1016/j.earscirev.2010.02.004

Seneviratne, S.I., Wilhelm, M., Stanelle, T., van den Hurk, B., Hagemann, S., Berg, A., Cheruy, F., Higgins, M.E., Meier, A., Brovkin, V., Claussen, M., Ducharne, A., Dufresne, J.-L., Findell, K.L., Ghattas, J., Lawrence, D.M., Malyshev, S., Rummukainen, M., Smith, B., 2013. Impact of soil moisture-climate feedbacks on CMIP5 projections: First results from the GLACE-CMIP5 experiment. Geophys. Res. Lett. 40, 5212-5217.

https://doi.org/https://doi.org/10.1002/grl.50956

Seo, H., Kim, Y., 2019. Interactive impacts of fire and vegetation dynamics on global carbon and water budget using Community Land Model version 4.5. Geosci. Model Dev. 12, 457-472. https://doi.org/10.5194/gmd-12-457-2019

Srinivasa Rao, C., Kareemulla, K., Krishnan, P., Murthy, G.R.K., Ramesh, P., Ananthan, P.S., Joshi, P.K., 2018. Agro-ecosystem based sustainability indicators for climate resilient agriculture in India: A conceptual framework. Ecol. Indic. 0-1. https://doi.org/10.1016/j.ecolind.2018.06.038

Stuart-Haëntjens, E., De Boeck, H.J., Lemoine, N.P., Mänd, P., Kröel-Dulay, G., Schmidt, I.K., Jentsch, A., Stampfli, A., Anderegg, W.R.L., Bahn, M., Kreyling, J., Wohlgemuth, T., Lloret, F., Classen, A.T., Gough, C.M., Smith, M.D., 2018. Mean annual precipitation predicts primary production resistance and resilience to extreme drought. Sci. Total Environ. 636, 360-366. https://doi.org/https://doi.org/10.1016/j.scitotenv.2018.04.290

Telesca, L., Lasaponara, R., Lanorte, A., 2008. Intra-annual dynamical persistent mechanisms in mediterranean ecosystems revealed SPOT-VEGETATION time series. Ecol. Complex. 5, 151-156. https://doi.org/https://doi.org/10.1016/j.ecocom.2007.10.001

Thornton, P.E., Lamarque, J.-F., Rosenbloom, N.A., Mahowald, N.M., 2007. Influence of carbonnitrogen cycle coupling on land model response to $\mathrm{CO} 2$ fertilization and climate variability. Global Biogeochem. Cycles 21. https://doi.org/https://doi.org/10.1029/2006GB002868

Toreti, A., Belward, A., Perez-Dominguez, I., Naumann, G., Luterbacher, J., Cronie, O., Seguini, L., Manfron, G., Lopez-Lozano, R., Baruth, B., van den Berg, M., Dentener, F., Ceglar, A., Chatzopoulos, T., Zampieri, M., 2019. The Exceptional 2018 European Water Seesaw Calls for Action on Adaptation. Earth's Futur. 7, 652-663. https://doi.org/10.1029/2019EF001170

Toreti, A., Deryng, D., Tubiello, F.N., Müller, C., Kimball, B.A., Moser, G., Boote, K., Asseng, S., Pugh, T.A.M., Vanuytrecht, E., Pleijel, H., Webber, H., Durand, J.-L., Dentener, F., Ceglar, A., Wang, X., Badeck, F., Lecerf, R., Wall, G.W., van den Berg, M., Hoegy, P., LopezLozano, R., Zampieri, M., Galmarini, S., O'Leary, G.J., Manderscheid, R., Mencos Contreras, E., Rosenzweig, C., 2020. Narrowing uncertainties in the effects of elevated CO2 on crops. Nat. Food 1, 775-782. https://doi.org/10.1038/s43016-020-00195-4

United Nations, 2016. Report of the Inter-Agency and Expert Group on Sustainable Development Goal Indicators. New York. https://doi.org/(E/CN.3/2016/2/Rev.1)

van der Molen, M.K., Dolman, A.J., Ciais, P., Eglin, T., Gobron, N., Law, B.E., Meir, P., Peters, W., Phillips, O.L., Reichstein, M., Chen, T., Dekker, S.C., Doubková, M., Friedl, M.A., Jung, M., van den Hurk, B.J.J.M., de Jeu, R.A.M., Kruijt, B., Ohta, T., Rebel, K.T., Plummer, S., Seneviratne, S.I., Sitch, S., Teuling, A.J., van der Werf, G.R., Wang, G., 2011. Drought and ecosystem carbon cycling. Agric. For. Meteorol. 151, 765-773. 
https://doi.org/https://doi.org/10.1016/j.agrformet.2011.01.018

Van Ruijven, J., Berendse, F., 2010. Diversity enhances community recovery, but not resistance, after drought. J. Ecol. 98, 81-86. https://doi.org/https://doi.org/10.1111/j.1365-

2745.2009.01603.x

Vargas, L., Willemen, L., Hein, L., 2019. Assessing the Capacity of Ecosystems to Supply Ecosystem Services Using Remote Sensing and An Ecosystem Accounting Approach. Environ. Manage. 63, 1-15. https://doi.org/10.1007/s00267-018-1110-x

Verduzco, V.S., Vivoni, E.R., Yépez, E.A., Rodríguez, J.C., Watts, C.J., Tarin, T., GaratuzaPayán, J., Robles-Morua, A., Ivanov, V.Y., 2018. Climate Change Impacts on Net Ecosystem Productivity in a Subtropical Shrubland of Northwestern México. J. Geophys. Res. Biogeosciences 123, 688-711. https://doi.org/10.1002/2017JG004361

Vogel, A., Scherer-Lorenzen, M., Weigelt, A., 2012. Grassland Resistance and Resilience after Drought Depends on Management Intensity and Species Richness. PLoS One 7, e36992.

Volodin, E.M., Mortikov, E. V, Kostrykin, S. V, Galin, V.Y., Lykossov, V.N., Gritsun, A.S., Diansky, N.A., Gusev, A. V, lakovlev, N.G., 2017. Simulation of the present-day climate with the climate model INMCM5. Clim. Dyn. 49, 3715-3734. https://doi.org/10.1007/s00382-0173539-7

Volterra, V., 1926. Variazioni e fluttuazioni del numero d'individui in specie animali conviventi. Mem. Acad. Lincei Roma 2, 31-113.

White, H.J., Gaul, W., Sadykova, D., León-Sánchez, L., Caplat, P., Emmerson, M.C., Yearsley, J.M., 2020. Quantifying large-scale ecosystem stability with remote sensing data. Remote Sens. Ecol. Conserv. 6, 354-365. https://doi.org/https://doi.org/10.1002/rse2.148

Williams, I.N., Torn, M.S., Riley, W.J., Wehner, M.F., 2014. Impacts of climate extremes on gross primary production under global warming. Environ. Res. Lett. 9, 94011. https://doi.org/10.1088/1748-9326/9/9/094011

Xiao, J., Liu, S., Stoy, P.C., 2016. Preface: Impacts of extreme climate events and disturbances on carbon dynamics. Biogeosciences 13, 3665-3675. https://doi.org/10.5194/bg-13-36652016

Xu, K., Wang, X., Jiang, C., Sun, O.J., 2020. Assessing the vulnerability of ecosystems to climate change based on climate exposure, vegetation stability and productivity. For. Ecosyst. 7, 23. https://doi.org/10.1186/s40663-020-00239-y

Zaccarelli, N., Li, B.-L., Petrosillo, I., Zurlini, G., 2013. Order and disorder in ecological timeseries: Introducing normalized spectral entropy. Ecol. Indic. 28, 22-30. https://doi.org/https://doi.org/10.1016/j.ecolind.2011.07.008

Zampieri, M., 2021. Reconciling the ecological and engineering definitions of resilience. Ecosphere. https://doi.org/https://doi.org/10.1002/ecs2.3375

Zampieri, M., Grizzetti, B., Meroni, M., Scoccimarro, E., Vrieling, A., Naumann, G., Toreti, A., 2019. Annual Green Water Resources and Vegetation Resilience Indicators: Definitions, Mutual Relationships, and Future Climate Projections. Remote Sens. 11, 2708. https://doi.org/10.3390/rs11222708 
Zampieri, M., Lionello, P., 2010. Simple statistical approach for computing land cover types and potential natural vegetation. Clim. Res. 41. https://doi.org/10.3354/cr00846

Zampieri, M., Toreti, A., Ceglar, A., de Palma, P., Chatzopoulos, T., 2020. Analysing the resilience of the European commodity production system with PyResPro, the Python Production Resilience package. arXiv.

Zampieri, Matteo, Toreti, A., Ceglar, A., Naumann, G., Turco, M., Tebaldi, C., 2020a. Climate resilience of the top ten wheat producers in the Mediterranean and the Middle East. Reg. Environ. Chang. 20, 41. https://doi.org/10.1007/s10113-020-01622-9

Zampieri, Matteo, Toreti, A., Ceglar, A., Palma, P. De, Chatzopoulos, T., 2020b. Analysing the resilience of the European commodity production system with PyResPro, the Python Production Resilience package. arXiv 2006.08976.

Zampieri, Matteo, Weissteiner, C.J., Grizzetti, B., Toreti, A., van den Berg, M., Dentener, F., 2020c. Estimating resilience of crop production systems: From theory to practice. Sci. Total Environ. 735, 139378. https://doi.org/https://doi.org/10.1016/j.scitotenv.2020.139378

Zhang, Z., Zhang, R., Cescatti, A., Wohlfahrt, G., Buchmann, N., Zhu, J., Chen, G., Moyano, F., Pumpanen, J., Hirano, T., Takagi, K., Merbold, L., 2017. Effect of climate warming on the annual terrestrial net ecosystem $\mathrm{CO} 2$ exchange globally in the boreal and temperate regions. Sci. Rep. 7, 3108. https://doi.org/10.1038/s41598-017-03386-5 
Figures and Tables

a) ssp126 2021-2050

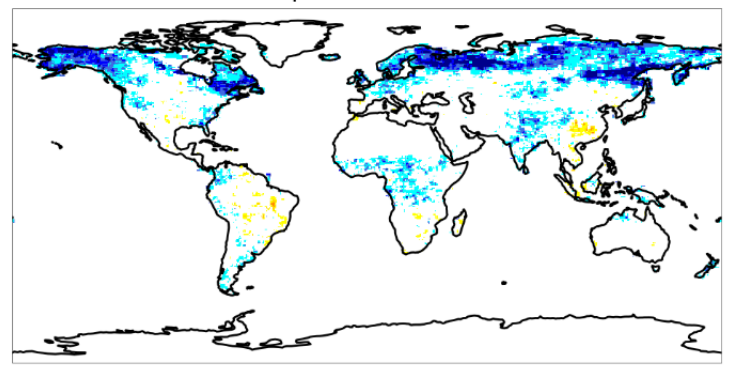

C) ssp245 2021-2050

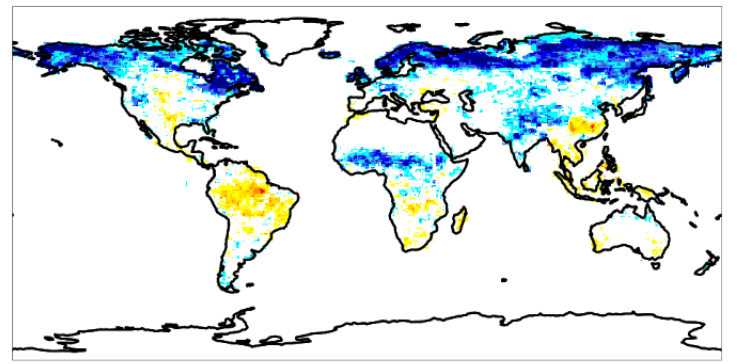

e) ssp585 2021-2050

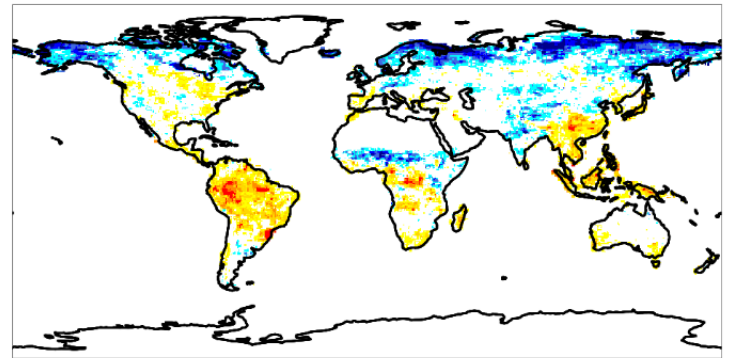

b) ssp126 2051-2100

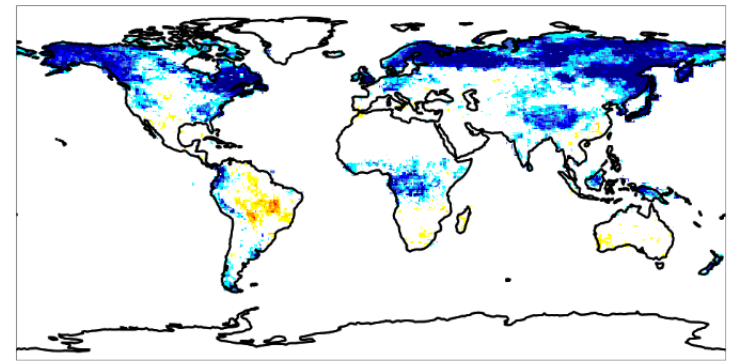

d) $\operatorname{ssp} 245$ 2051-2100

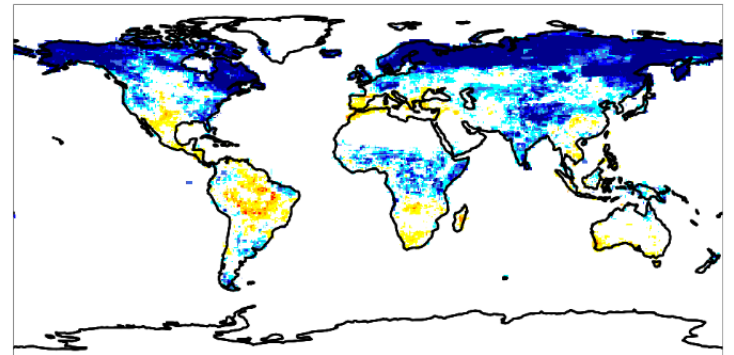

f) $\operatorname{ssp} 5852051-2100$

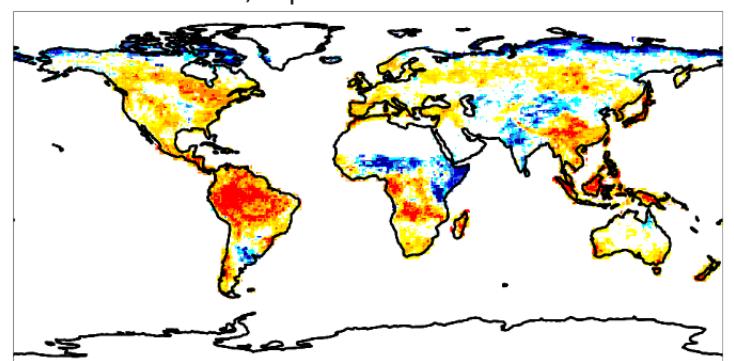

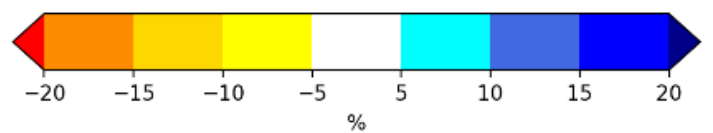

Figure 1. Global changes of annual gross primary production resilience (Rp) computed from an ensemble of 16 Earth System Models (ESMs) simulations under ssp126 (panels a and b), ssp245 (panels c and d), and ssp585 (panels e and f) CMIP6 scenarios in the periods 2021-2050 (panels a, c, and e) and 2051-2100 (panels b, d, and f) compared to the period 1985-2014. 
a) ssp126 2021-2050

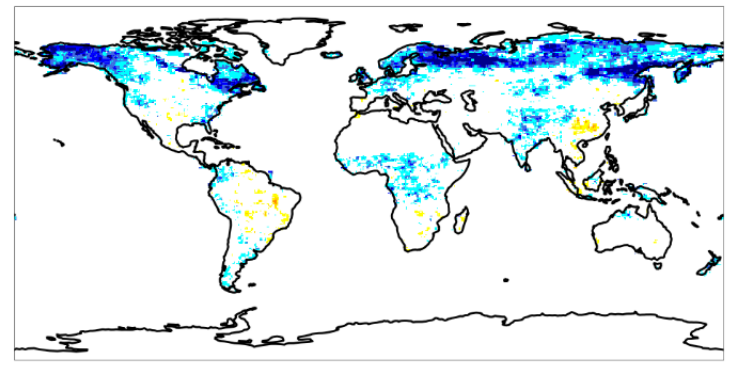

c) $\operatorname{ssp} 2452021-2050$

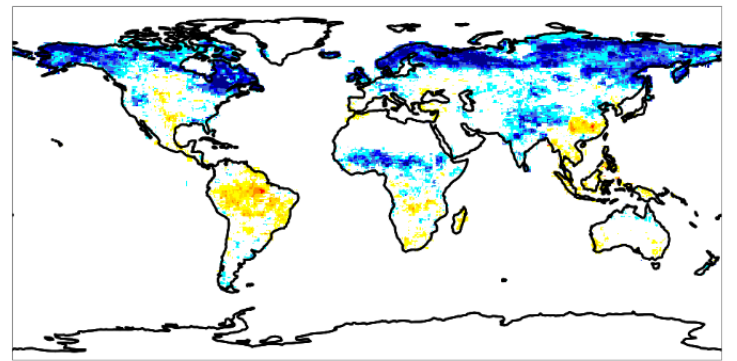

e) ssp585 2021-2050

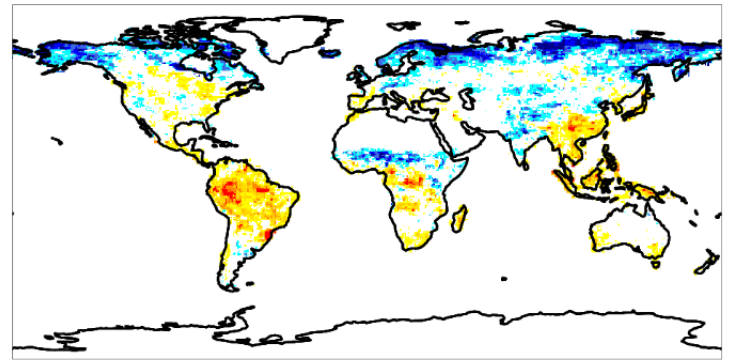

b) ssp126 2051-2100

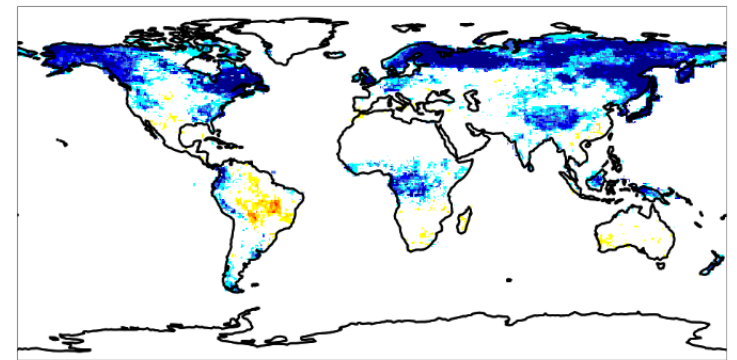

d) ssp245 2051-2100

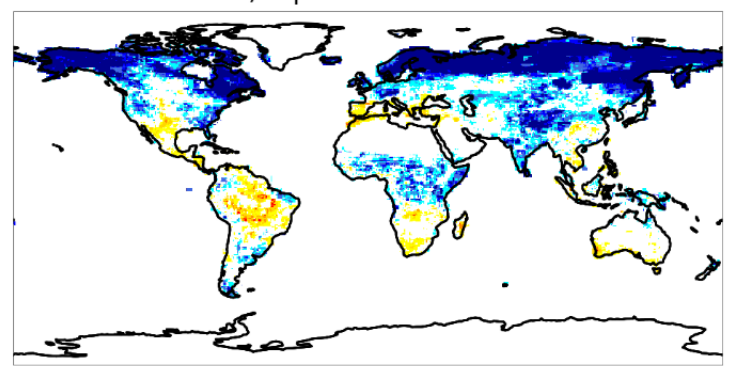

f) $\operatorname{ssp} 5852051-2100$

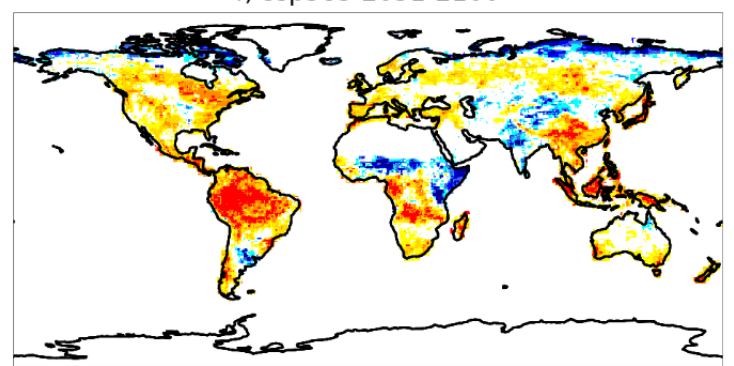

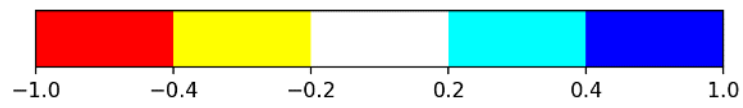

Figure 2. Ensemble mean share of the two factors triggering changes in the vegetation annual production resilience indicator (as from eq. 5, see Methods). Positive values (light and dark blue areas) point to changes in the resilience indicator mainly due to changes in the mean GPP. Negative values (red and yellow areas) are associated with grid points where the changes in the resilience indicator are mainly driven by changes in the GPP variability. 


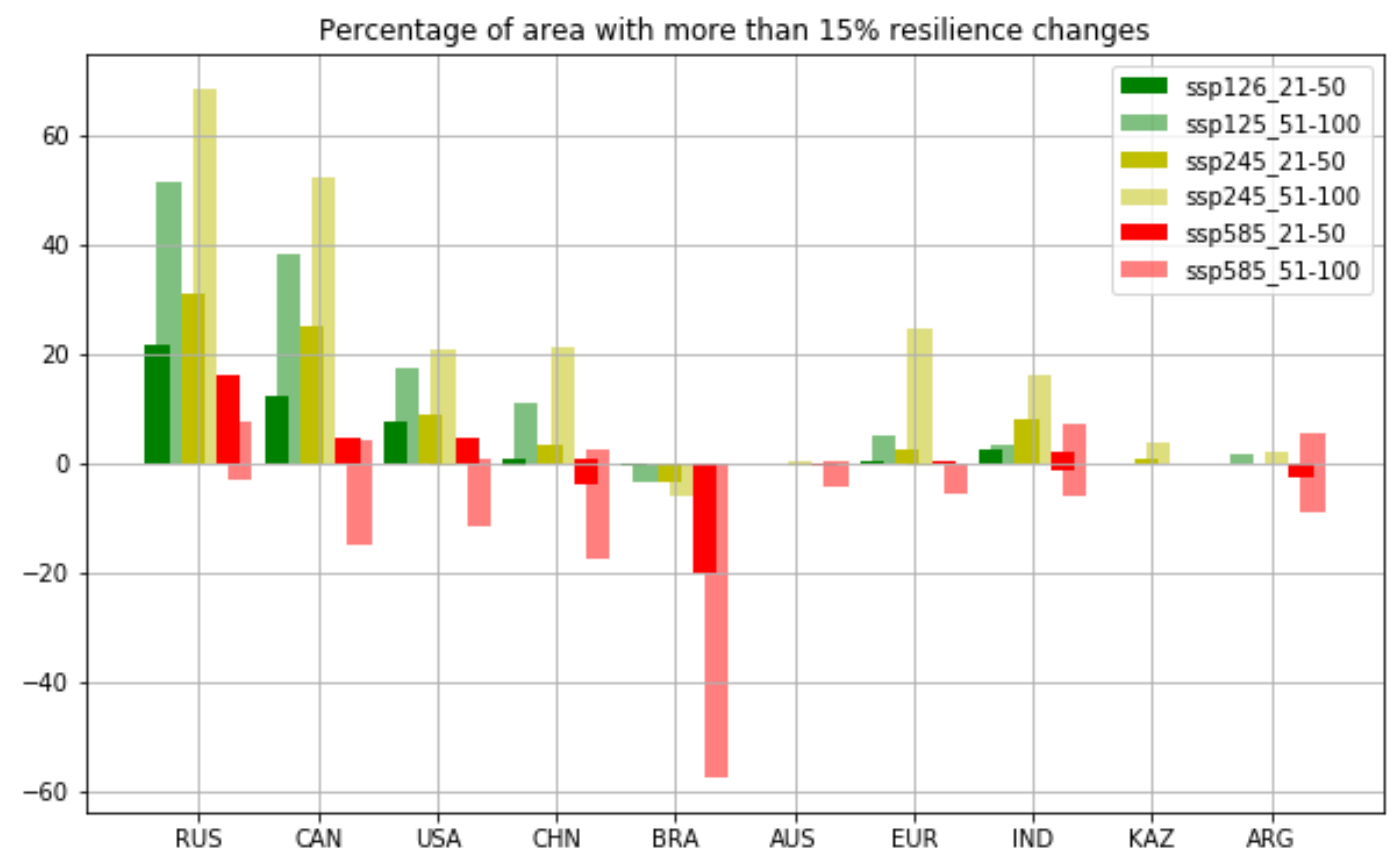

Figure 3. Percentages of area with more than 15\% annual GPP resilience change for the ten wider countries, Russia (RUS), Canada (CAN), the United States of America (USA), China (CHN), Brazil (BRA), Australia (AUS), the European Union (EUR), India (IND), Kazakhstan (KAZ), and Argentina (ARG). Negative values refer to the percentage of areas with negative GPP resilience changes. 
Table 1. Earth System Model (ESMs) simulations producing the annual gross primary production (GPP) data used in this study; with information on: modules delegated to the representation of land surface processes and GPP simulations (and associated reference publications); number of simulations available up to 31st December 2019 for the historical period and for ssp126, ssp245 and ssp585 future scenarios.

\begin{tabular}{|l|l|l|l|l|l|}
\hline ESM & Land Model & historical & ssp126 & ssp245 & ssp585 \\
\hline ACCESS-ESM-5 & $\begin{array}{l}\text { CABLE w/Carbon cycle (De } \\
\text { Kauwe et al., 2015) }\end{array}$ & 1 & 1 & 1 \\
\hline CESM2-WACCM & CLM5 (Lawrence et al., 2019) & 3 & 1 & 1 & 1 \\
\hline CESM2 & CLM5 (Lawrence et al., 2019) & 10 & 2 & 3 & 2 \\
\hline CNRM-CM6-1 & $\begin{array}{l}\text { ISBA with fixed LAl monthly } \\
\text { climatology (Garrigues et al., } \\
\text { 2015a, 2015b) }\end{array}$ & 30 & 6 & 6 \\
\hline CNRM-ESM-1 & $\begin{array}{l}\text { ISBA with interactive LAI } \\
\text { (Garrigues et al., 2015b, 2015a) }\end{array}$ & 7 & 1 & 5 & 5 \\
\hline $\begin{array}{l}\text { CLASS-CTEM (Arora and } \\
\text { CanOE }\end{array}$ & 3 & 3 & 3 & 3 \\
\hline CanESM5 & $\begin{array}{l}\text { CLASS-CTEM (Arora and } \\
\text { Scinocca, 2016) }\end{array}$ & 50 & 50 & 50 & 50 \\
\hline EC-Earth3-Veg & $\begin{array}{l}\text { LPJ-GUESS v4 (Forrest et al., } \\
\text { 2018) }\end{array}$ & 4 & 3 & 3 & 3 \\
\hline INM-CM4-8 & no name (Volodin et al., 2017) & 1 & 1 & 1 & 1 \\
\hline INM-CM5-0 & no name5 & 10 & 1 & 1 & 1 \\
\hline IPSL-CM6A-LR & ORCHIDEE (Chen et al., 2016) & 30 & 1 & 9 & 6 \\
\hline MIROC-ES2L & VISIT-e (Ito and Inatomi, 2011) & 3 & 1 & 1 & 1 \\
\hline MPI-ESM1-2-HR & JSBACH (Reick et al., 2013) & 10 & 2 & 2 & 2 \\
\hline MPI-ESM2-2-LR & JSBACH (Reick et al., 2013) & 10 & 10 & 10 & 10 \\
\hline NorESM2-LM & GFDL-LM3.0 (Gerber et al., 2010) & 3 & 1 & 3 & 1 \\
\hline UKEMS1-0-LL & JULES (Harper et al., 2016) & 19 & 5 & 4 & 5 \\
\hline
\end{tabular}


Table 2. Fraction of global land area where the relative resilience indicator $\left(\Delta R_{p} / R_{p}\right)$ exceeds different thresholds $(5 \% ; 10 \% ; 15 \% ; 20 \%)$ in the simulation ensemble median. The first estimation (third and fourth columns) considers all areas displaying changes larger than the thresholds. A second estimate (fifth and sixth columns) is restricted to the areas where at least the $75 \%$ of the models agree on the sign of changes.

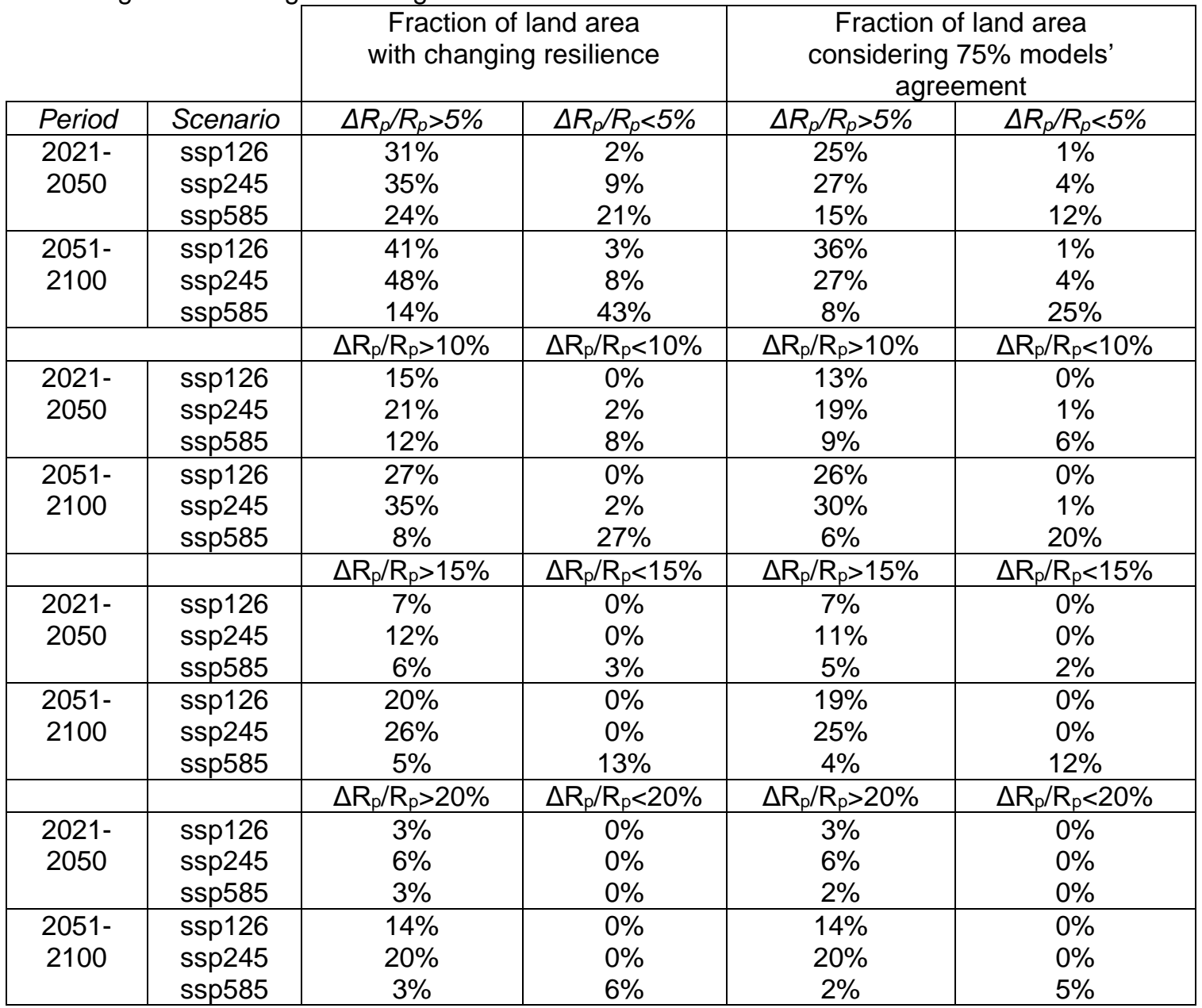


Rise and fall of vegetation primary production resilience to climate variability anticipated by a large ensemble of Earth System Models' simulations.

\section{SUPPLEMENTARY MATERIAL}

non-peer reviewed preprint submitted to EarthArXiv

Matteo Zampieri, Bruna Grizzetti, Andrea Toreti, Pierluca De Palma and Alessio Collalti

matteo.zampieri@ec.europa.eu 


\title{
APPENDIX A:
}

\section{Definition and properties of the annual production resilience indicator $\left(\mathbf{R}_{\mathrm{p}}\right)$}

\begin{abstract}
Assumptions
This theory focusses on production, which is a main ecosystem function. Other functions and features such as the internal structure and the relationships with the environment are not explicitly accounted for by the annual production resilience indicator.

The ecological and engineering definitions of resilience require the identification and the measurement of the system perturbations. Assuming that the larger perturbations are rarer compared to the smaller ones and that the larger perturbations result in larger production losses than the smaller ones, it is possible to quantify the amplitude of different types of perturbations and their combinations by a unique unit of measure that is the return period of the production losses $\left(T^{*}\right)$. For annual production systems, $T^{*}$ is the average number of years (or equivalently the inverse frequency) between events producing production losses of a certain amount.
\end{abstract}

\section{Ecological resilience of homogeneous production systems ${ }^{1}$}

This section describes the consistency between the annual production resilience indicator and the ecological definition of resilience. Following the Holling's definition of ecological resilience, we can define the annual production resilience as:

(1) $R_{\text {ecol }}=T^{*}$ Max,

where $T^{*}$ Max is the largest pressure that the system can absorb before losing its production, measured by the return period of such events.

Using this definition, it is possible to demonstrate that production resilience can be estimated by the annual production resilience indicator:

(2) $R_{p}=\mu^{2} / \sigma^{2}$,

where $\mu$ is the mean and $\sigma$ the standard deviation of the production time-series.

The equivalence between equation 1 and 2 can be demonstrated for production systems that are homogeneous in space and time, meaning that the perturbations and the system response are spatially constant and that their statistical properties are stationary in time.

In the case the system production is binomially distributed, i.e., the annual production values are either the optimal production $P$ in the years where $T^{*}<T^{*}$ Max or zero in the years $T^{*}>T^{*} \operatorname{Max}$, the mean and the variance of the production are:

(3) $\quad \mu=P(1-f)$, and

(4) $\sigma^{2}=P^{2}(1-f) f$,

where $f$ is $1 / T^{*} M a x$, the frequency of the years with zero production, which is assumed to be much smaller than the frequency of years with optimal production (adapted system). By combining equation 2 with 3 and 4 one obtains:

(5) $R_{p}=(1-f) / f \approx 1 / f=R_{e c o l} \quad$ Q.E.D. 
A more general relationship between the annual production resilience indicator $\left(R_{p}\right)$ and the ecological resilience can be obtain with a modelling approach allowing the system to lose some of the production also for more common perturbations $\left(T^{*}<T^{*}\right.$ Max $)$, leading to the relationship:

(6) $R_{p}=\alpha \cdot R_{e c o l}, 0<\alpha<1$

where $\alpha$ decreases the more the system is sensitive to common perturbations and the more the system bears the memory of the losses of the previous year, compromising the current year production.

\section{Engineering resilience versus ecological resilience ${ }^{2}$}

This section describes the consistency between the ecological and engineering definitions of resilience for a special case. The engineering definition of resilience refers to the timing that the system takes to return to the equilibrium state after a disturbance and to recover its functional capacity.

In case of a linear production system, where the production is cumulated constantly in time and the return timing is proportional to the amplitude of the perturbance, it is possible to demonstrate the equivalence between the ecological and the engineering definitions of resilience.

Let $\Delta p$ be the departure from the potential production $(P)$ recorded at the end of the production cycle as a consequence of the perturbation that occurred during the production period. Let $d t$ be the restoring time. No production takes place during this time.

Assuming a linear dependency between the production loss and that rareness of the event, the loss of production can be written as

(7) $\Delta p^{\prime}=d p^{\prime} / d T^{*} \cdot T^{*}$,

where ' $d p^{\prime} / d T^{*}$ ' is the derivative of the normalized production anomaly with respect to the amplitude of the perturbation. Using the chain rule of the derivative:

(8) $\Delta p^{\prime}=d p^{\prime} / d t^{\prime} \cdot d t^{\prime} / d T^{*} \cdot T^{*}$.

The first factor of equation $8\left(d p^{\prime} / d t^{\prime}\right)$ represents the derivative of the normalized production loss with respect to the normalized recovering time, which, under the linearity assumption, is equal to one because if the restoring time takes the entire production season $\left(d t^{\prime}=1\right)$, all the production is lost $\left(d p^{\prime}=1\right)$. So, this term can be eliminated by the equation, leading to:

(9) $\Delta p^{\prime}=d t^{\prime} / d T^{*} \cdot T^{*}$.

The factor $d t^{\prime} / d T^{*}$ in equations 8 and 9 is the derivative of the normalized recovering time with respect to the amplitude of the perturbation, measured by its return period. Thus, it represents the dependency of the production system recovering time from the amplitude of the perturbation. This term is clearly linkable to the engineering definition of resilience $\left(R_{\text {engin }}\right)$ :

(10) $R_{\text {engin }}=1 /\left(d t^{\prime} / d T^{*}\right)$.

In fact, according to equation 10, when considering systems that are subject to the same external forcing, the more resilient system will be the one that returns more quickly to the normal functioning. If $R_{\text {engin }}$ is infinite, the recovering is instantaneous $\left(d t^{\prime}=0\right)$ and there is no loss of production.

Using equations 9 and 10 and rearranging terms, $R_{\text {engin }}$ can be written as the ratio between the return period of the external forcing and the normalized production anomaly: 
(11) $R_{\text {engin }}=T^{*} / \Delta p^{\prime}$.

Evaluating equation (10) for $T^{*}=T^{*}{ }_{M A X}$ and $\Delta p^{\prime}=1$, one obtains:

(12) $R_{\text {engin }}=T^{\star}{ }_{\text {MAX }}=R_{\text {ecol }}$

which is the ecological definition of resilience Q.E.D..

Therefore, the annual production resilience indicator is in principle consistent with the engineering definition of resilience as well. However, the assumption of linearity of the production system is seldom verified in real production system. This assumption is invoked in this section only and does not affect the rest of the theory.

\section{Non-stationary production systems ${ }^{3}$}

The annual production resilience indicator $\left(R_{p}\right)$ is not well-defined for time-series where the production mean is changing in time, because the mean and the standard deviation are ill-defined in the first place. In this case, it is possible to normalize the production time-series by a moving average, of by a non-linear fitting algorithm before computing $R_{p}$.

In case the time-series is stationary, this procedure does not change the annual production resilience value. In case it is not, it allows to remove the trend accounting for the fluctuations proportionally, so that the departures from the mean in the periods with higher production are not penalized with respect to those with lower production.

\section{Heterogeneous production systems - Effects of diversity on production resilience ${ }^{1}$}

Real production systems are often characterized by some degree of spatial variability of the perturbations and of the production response by different species ( $\gamma$-diversity). The production timeseries recorded from spatially heterogeneous systems can be treated as the linear superposition of individual homogeneous production systems. In this case, the effect of diversity on the value annual production resilience indicator computed from the total production time-series can be easily understood by induction. Let us consider a production system composed of two independent production sources. The mean and the variance of this production system are:

(13) $\mu_{T O T}=\mu_{1}+\mu_{2}$, and

(14) $\sigma^{2}$ TOT $=\sigma^{2}{ }_{1}+\sigma^{2}{ }_{2}+2 \cdot \operatorname{Cov}_{1,2}$

where Cov is the covariance between the two production time-series.

If the time-series have same mean and standard deviation and they are not correlated with each other, the annual production resilience indicator of the sum is exactly the double of that of the individual time-series. In case they are totally correlated, the total production resilience equals that of the individual time-series. Whereas, if they are totally anticorrelated, the individual fluctuations are exactly balanced between each other, the variance is zero and the total production resilience indicator becomes infinite.

In case there are $n$ uncorrelated time-series with same mean and variance, the annual production resilience of their sum is exactly $n$-times the value of the individual time series and the probability of total production loss gets extremely low. This is the reason why total production loss is very rarely observed in production time-series recorded over large areas. In case the total production is unevenly distributed among the different time series, the time-series with larger production contributed proportionally more than the others. In case the time-series are partially 
correlated/anticorrelated, they contribute less/more to the increase of total production resilience. In case there is a component of the system that does not contribute to resilience such as nonvegetated area within the region under evaluation, this is not contributing to the total production resilience and does not change the value of the annual production resilience indictor ${ }^{4}$.

\section{Accuracy of the annual production resilience indicator ${ }^{1}$}

The accuracy of $R_{p}$ can be evaluated by Monte-Carlo experiments. For normally distributed timeseries, which often characterize real production systems, the sampling error of the annual production resilience indicator is roughly the $30 \%$, if computed on time-series of about 30 numbers. Other reference values can be inferred from a look up table.

\section{References}

1. Zampieri, M. et al. Estimating resilience of crop production systems: From theory to practice. Sci. Total Environ. 735, 139378 (2020).

2. Zampieri, M. Reconciling the ecological and engineering definitions of resilience. Ecosphere (2021) doi:https://doi.org/10.1002/ecs2.3375.

3. Zampieri, M. et al. Climate resilience of the top ten wheat producers in the Mediterranean and the Middle East. Reg. Environ. Chang. 20, 41 (2020).

4. Zampieri, M. et al. Annual Green Water Resources and Vegetation Resilience Indicators: Definitions, Mutual Relationships, and Future Climate Projections. Remote Sens. 11, 2708 (2019). 


\section{APPENDIX B}

\section{Supplementary Figures and Tables}

Figure S1 S2 S3 and the second column of Table S2 can be qualitatively compared to Zampieri et al. ${ }^{4}$, where vegetation production for a similar period (1982-2015 instead of 1985-2014) was estimated using the Normalized Differential Vegetation Index (NDVI) measured by remote sensing as proxy of the observed gross primary production. It is worth noting that in Zampieri et al. the annual NDVI mean was computed from January to December, not considering the shift in growing seasons as in the present paper.

Fig S1: ensemble median GPP average (Kg/year)
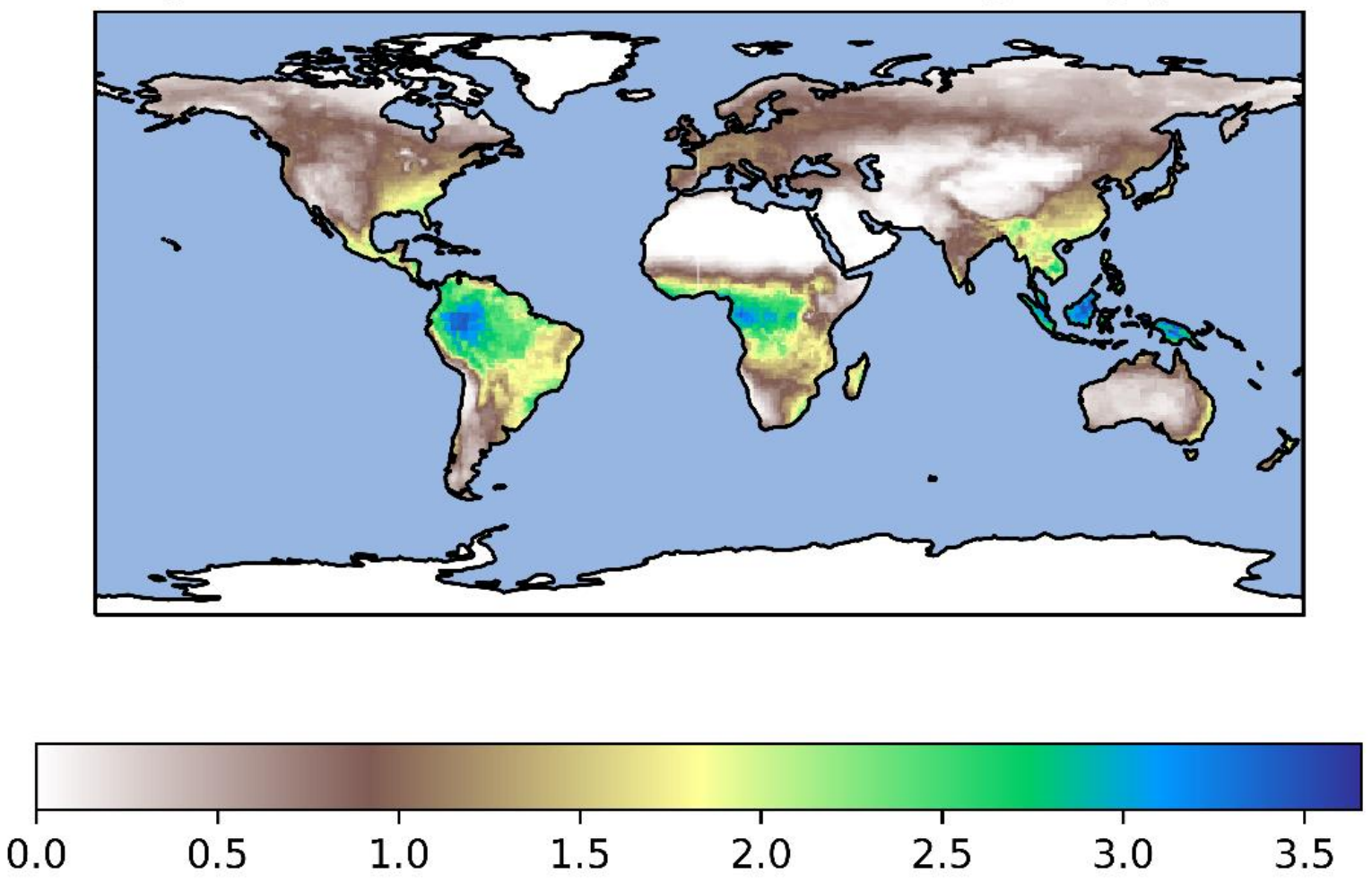
Fig S2: ensemble GPP variability ( $\mathrm{Kg} / \mathrm{year}$ )
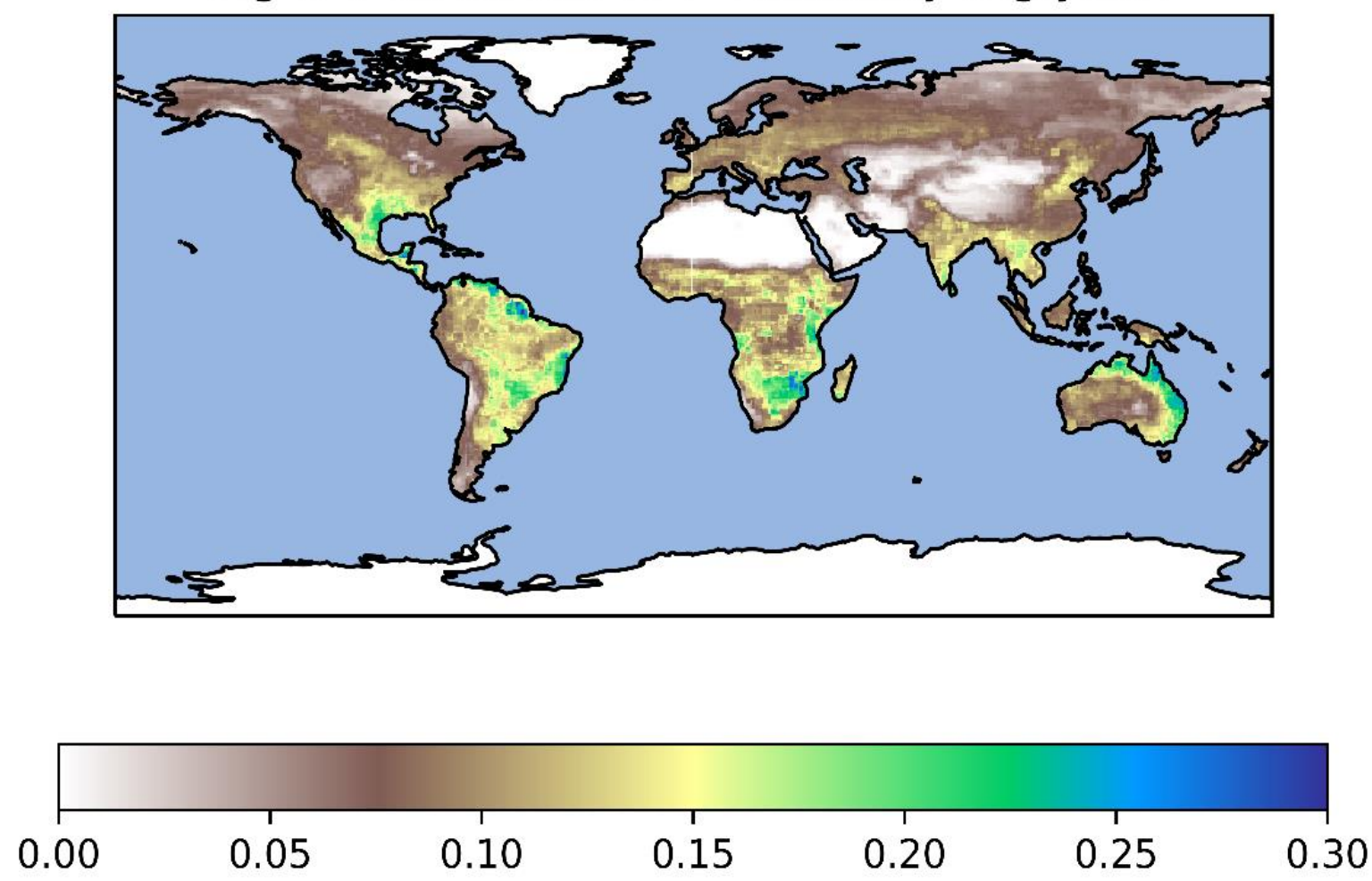
Fig S3: ensemble GPP resilience log10(Rv)
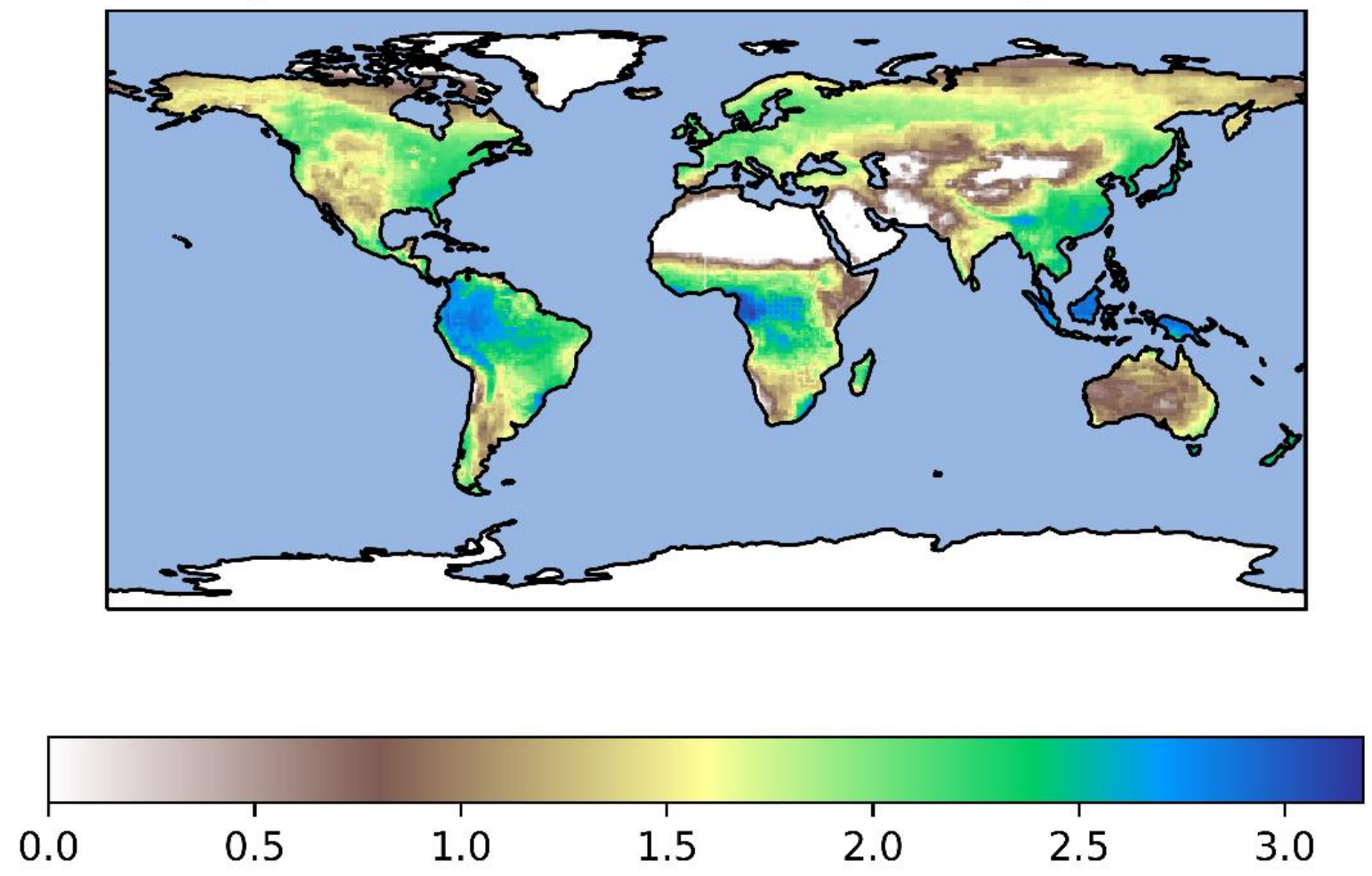
a) ssp126 2021-2050

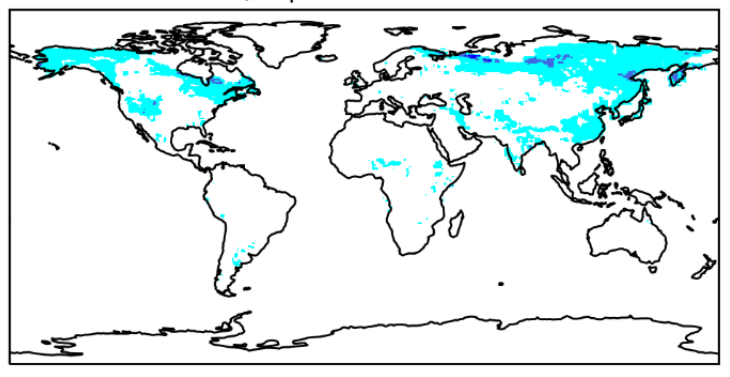

c) ssp245 2021-2050

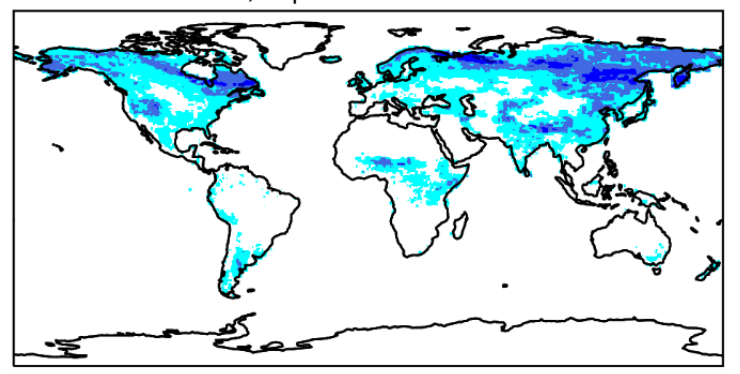

e) ssp585 2021-2050

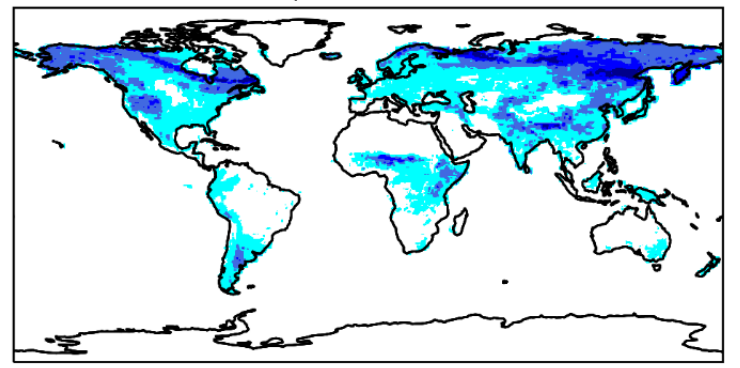

b) ssp126 2051-2100

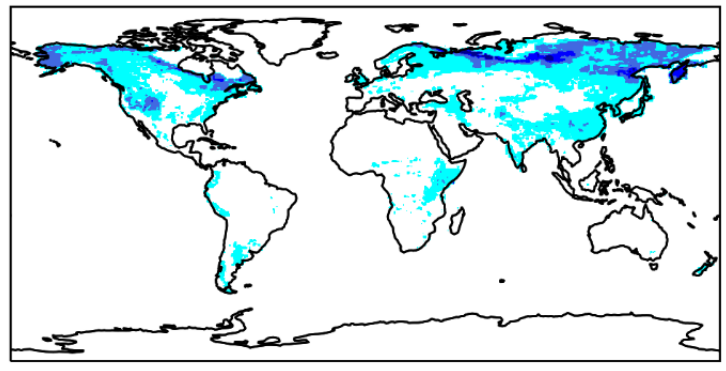

d) ssp245 2051-2100

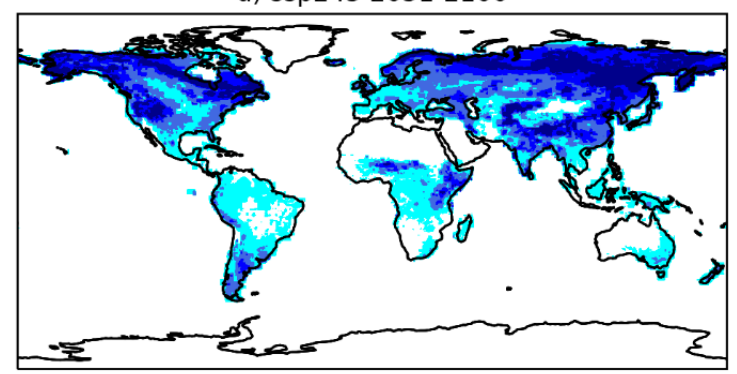

f) $\operatorname{ssp} 5852051-2100$

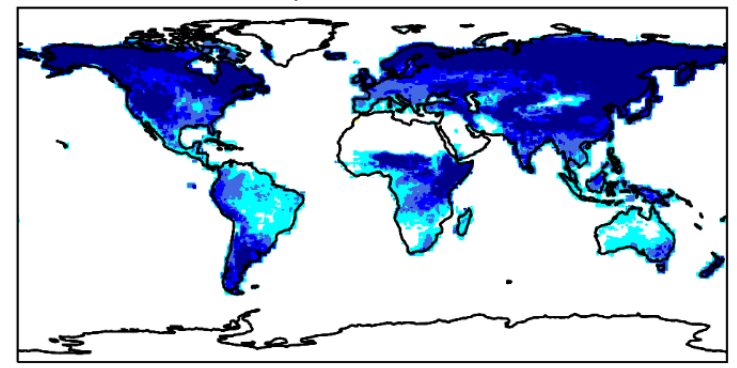

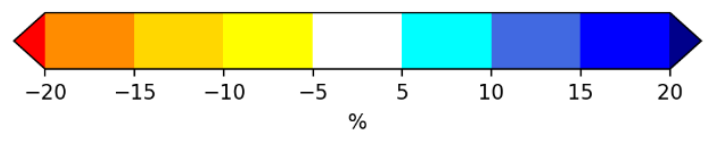

Figure S4. Global changes of annual gross primary production computed from an ensemble of 16 Earth System Models (ESMs) simulations under ssp126 (panels a and b), ssp245 (panels c and d), and ssp585 (panels e and f) CMIP6 scenarios in the periods 2021-2050 (panels a, c, and e) and 2051-2100 (panels b, d, and f) compared to the period 1985-2014. 
a) ssp126 2021-2050

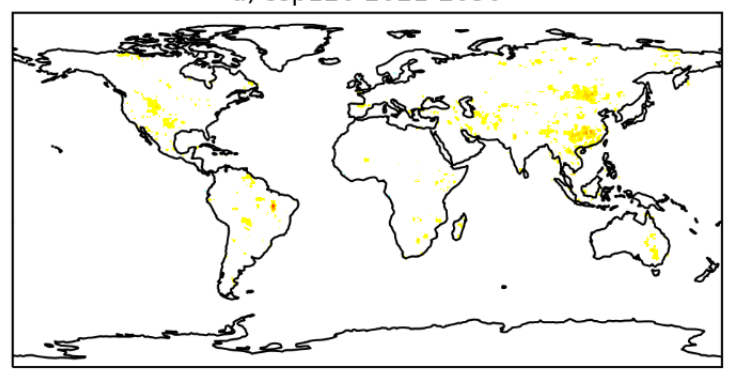

c) $\operatorname{ssp} 2452021-2050$

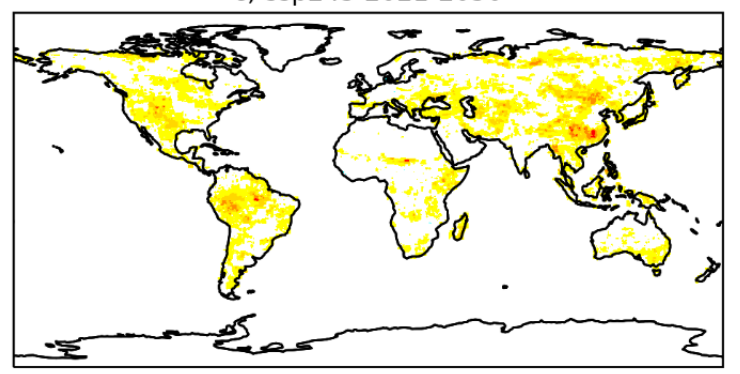

e) ssp585 2021-2050

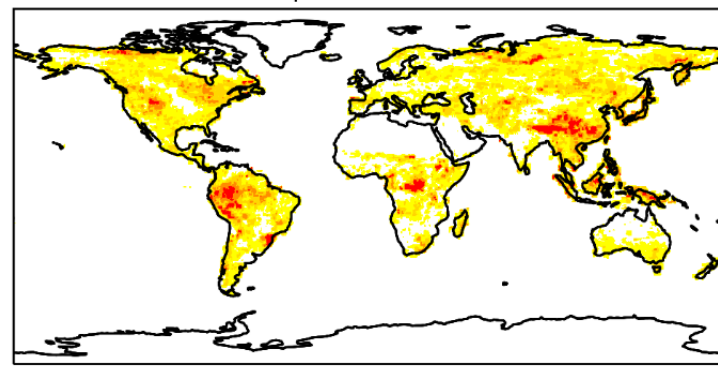

b) ssp126 2051-2100

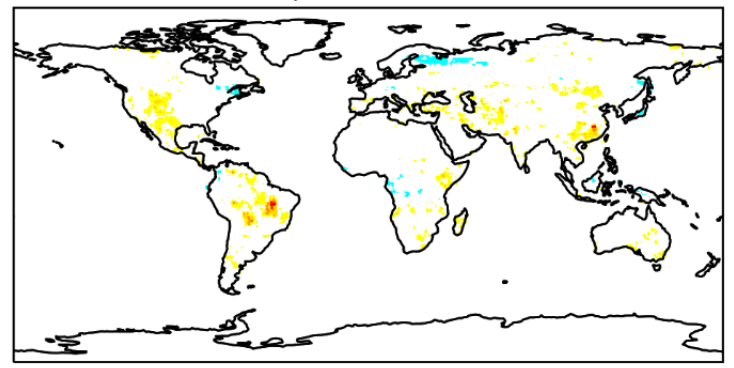

d) ssp245 2051-2100

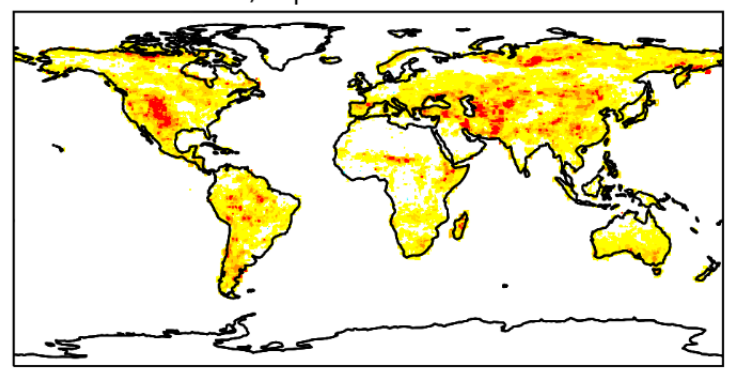

f) $\operatorname{spp585~2051-2100~}$

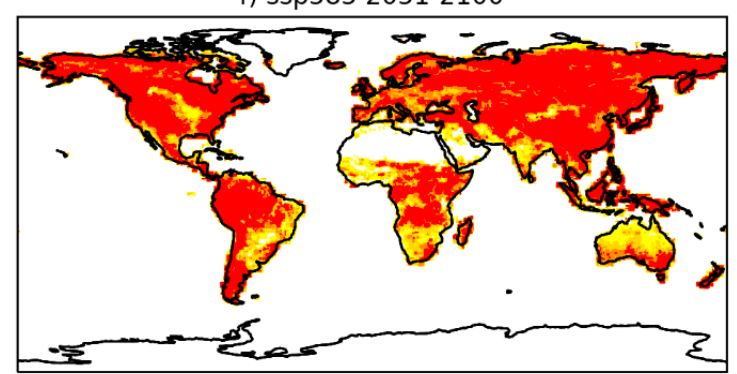

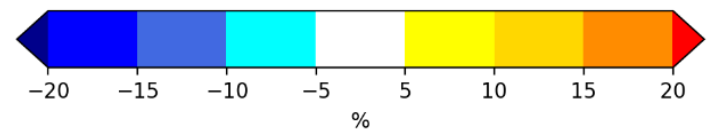

Figure S5. Global changes of annual gross primary production standard deviation computed from an ensemble of 16 Earth System Models (ESMs) simulations under ssp126 (panels a and b), ssp245 (panels $c$ and d), and ssp585 (panels e and f) CMIP6 scenarios in the periods 2021-2050 (panels a, c, and e) and 2051-2100 (panels b, d, and f) compared to the period 1985-2014.

Table S1: Koppen Climates classification (koeppen-geiger.vu-wien.ac.at)

\begin{tabular}{|l|l|l|l|}
\hline Main Climates & Precipitation & Temperature & \\
\hline A: equatorial & W: desert & h: hot arid & F: polar frost \\
\hline B: arid & S: steppe & k: cold arid & T: polar tundra \\
\hline C: warm temperature & f: fully humid & a: hot summer & \\
\hline D: snow & s: summer dry & b: warm summer & \\
\hline E: polar & w: winter dry & c: cool summer & \\
\hline & m: monsoonal & $\begin{array}{l}\text { d: extremely } \\
\text { continental }\end{array}$ & \\
\hline
\end{tabular}


Table S2: Fraction of biome areas where the relative resilience indicator $\left(\Delta R_{p} / R_{p}\right)$ exceeds the $15 \%$ in the simulation ensemble median in the Green Road scenario (ssp126) in 2021-2051 (g) and in 2051-2100 (G), in the Middle of the Road scenario (ssp245) in 2021-2051 (m) and in 2051-2100 (M) and in the Fossil Fuel scenario (ssp585) in 2021-2051 (f) and in 2051-2100 (F). Plus and minus signs refer to positive and negative changes, i.e. $\Delta R_{p} / R_{p}>15 \%$ and $\Delta R_{p} / R_{p}>15 \%$, respectively. The biome areas are considered according to the Koppen-climates classifications (see Table 1). The spatial distribution of Koppen-climates classification has been downloaded from koeppengeiger.vu-wien.ac.at 


\begin{tabular}{|c|c|c|c|c|c|c|c|c|c|c|c|c|c|}
\hline Clim & Mean $\mathbf{R}_{\mathrm{p}}$ & $g+$ & $\mathrm{G}_{+}$ & $\mathbf{m +}$ & M+ & $f+$ & $\mathbf{F +}$ & g- & G- & m- & M- & f- & F- \\
\hline Af & $491 \pm 235$ & 0 & 0 & 0 & 9 & 2 & 0 & 0 & 1 & 22 & 0 & 1 & 65 \\
\hline $\mathrm{Am}$ & $290 \pm 206$ & 0 & 0 & 0 & 6 & 2 & 0 & 0 & 5 & 14 & 0 & 3 & 48 \\
\hline As & $132 \pm 255$ & 1 & 2 & 0 & 8 & 5 & 4 & 0 & 0 & 0 & 0 & 0 & 10 \\
\hline Aw & $154 \pm 161$ & 0 & 3 & 1 & 4 & 4 & 3 & 0 & 1 & 3 & 2 & 2 & 26 \\
\hline BWk & $5 \pm 9$ & 0 & 1 & 0 & 0 & 11 & 4 & 0 & 0 & 0 & 0 & 0 & 0 \\
\hline BWh & $3 \pm 12$ & 0 & 0 & 0 & 0 & 1 & 3 & 0 & 0 & 0 & 0 & 0 & 0 \\
\hline BSk & $21 \pm 26$ & 0 & 0 & 0 & 1 & 3 & 0 & 0 & 0 & 0 & 0 & 0 & 5 \\
\hline BSh & $26 \pm 35$ & 0 & 5 & 3 & 0 & 6 & 9 & 0 & 0 & 0 & 0 & 0 & 4 \\
\hline Cfa & $156 \pm 134$ & 0 & 0 & 0 & 9 & 4 & 2 & 0 & 1 & 5 & 0 & 0 & 16 \\
\hline $\mathrm{Cfb}$ & $138 \pm 116$ & 1 & 6 & 1 & 11 & 10 & 1 & 0 & 0 & 2 & 0 & 1 & 18 \\
\hline Cfc & $120 \pm 78$ & 1 & 11 & 2 & 12 & 11 & 0 & 0 & 0 & 2 & 0 & 0 & 24 \\
\hline Csa & $29 \pm 22$ & 1 & 2 & 2 & 0 & 2 & 3 & 0 & 0 & 0 & 0 & 3 & 16 \\
\hline Csb & $75 \pm 64$ & 0 & 0 & 0 & 1 & 1 & 0 & 0 & 0 & 0 & 0 & 0 & 16 \\
\hline Csc & $62 \pm 28$ & 0 & 0 & 0 & 0 & 9 & 0 & 0 & 0 & 0 & 0 & 0 & 45 \\
\hline Cwa & $150 \pm 102$ & 0 & 2 & 0 & 2 & 1 & 1 & 0 & 1 & 6 & 0 & 1 & 34 \\
\hline Cwb & $180 \pm 113$ & 0 & 2 & 1 & 10 & 5 & 3 & 0 & 3 & 13 & 0 & 2 & 54 \\
\hline Cwc & $160 \pm 87$ & 0 & 0 & 0 & 10 & 0 & 0 & 0 & 0 & 0 & 0 & 0 & 80 \\
\hline Dfa & $50 \pm 45$ & 0 & 1 & 0 & 1 & 4 & 0 & 0 & 0 & 0 & 0 & 0 & 2 \\
\hline Dfb & $81 \pm 52$ & 3 & 6 & 0 & 17 & 22 & 0 & 0 & 0 & 0 & 0 & 0 & 14 \\
\hline Dfc & $51 \pm 35$ & 25 & 40 & 16 & 57 & 77 & 5 & 0 & 0 & 0 & 0 & 0 & 6 \\
\hline Dfd & $22 \pm 13$ & 19 & 51 & 40 & 71 & 83 & 30 & 0 & 0 & 0 & 0 & 0 & 0 \\
\hline Dsa & $20 \pm 11$ & 0 & 1 & 0 & 0 & 1 & 0 & 0 & 0 & 0 & 0 & 0 & 1 \\
\hline Dsb & $42 \pm 31$ & 0 & 0 & 1 & 1 & 2 & 0 & 0 & 0 & 0 & 0 & 1 & 10 \\
\hline Dsc & $36 \pm 24$ & 36 & 29 & 10 & 68 & 79 & 0 & 0 & 0 & 0 & 0 & 0 & 2 \\
\hline Dwa & $107 \pm 69$ & 0 & 0 & 0 & 4 & 7 & 1 & 0 & 0 & 0 & 0 & 0 & 4 \\
\hline Dwb & $115 \pm 73$ & 2 & 1 & 0 & 28 & 21 & 0 & 0 & 0 & 1 & 0 & 0 & 12 \\
\hline Dwc & $57 \pm 32$ & 22 & 17 & 1 & 52 & 53 & 0 & 0 & 0 & 0 & 0 & 0 & 12 \\
\hline Dwd & $32 \pm 8$ & 8 & 51 & 10 & 89 & 98 & 0 & 0 & 0 & 0 & 0 & 0 & 0 \\
\hline ET & $14 \pm 30$ & 8 & 21 & 15 & 26 & 58 & 18 & 0 & 0 & 0 & 0 & 0 & 2 \\
\hline EF & $0 \pm 0$ & 0 & 0 & 0 & 0 & 0 & 0 & 0 & 0 & 0 & 0 & 0 & 0 \\
\hline
\end{tabular}

Table S3. Fraction of country areas where the relative resilience indicator $\left(\Delta R_{p} / R_{p}\right)$ exceeds the $15 \%$ in the simulation ensemble median in the Green Road scenario (ssp126) in 2021-2051 (g) and in 2051-2100 (G), in the Middle of the Road scenario (ssp245) in 2021-2051 (m) and in 20512100 (M) and in the Fossil Fuel scenario (ssp585) in 2021-2051 (f) and in 2051-2100 (F). Plus and minus signs refer to positive and negative changes, i.e. $\Delta R_{p} / R_{p}>15 \%$ and $\Delta R_{p} / R_{p}>15 \%$, respectively. 


\begin{tabular}{|c|c|c|c|c|c|c|c|c|c|c|c|c|c|}
\hline ISO3 & g+ & $\mathbf{G +}$ & $m+$ & M+ & $f+$ & $\mathbf{F +}$ & g- & G- & m- & M- & $f-$ & F- & Country Name \\
\hline ARE & 0 & 0 & 0 & 0 & 0 & 0 & 0 & 0 & 0 & 0 & 0 & 0 & United Arab Emirates \\
\hline $\mathrm{AFG}$ & 0 & 0 & 0 & 2 & 1 & 0 & 0 & 0 & 0 & 0 & 0 & 0 & Afghanistan \\
\hline ALB & 0 & 0 & 0 & 0 & 0 & 0 & 0 & 0 & 0 & 0 & 0 & 0 & Albania \\
\hline ARM & 0 & 0 & 0 & 0 & 0 & 0 & 0 & 0 & 0 & 0 & 0 & 8 & Armenia \\
\hline AGO & 0 & 1 & 0 & 4 & 0 & 1 & 0 & 0 & 0 & 0 & 7 & 45 & Angola \\
\hline ATA & 0 & 0 & 0 & 0 & 0 & 0 & 0 & 0 & 0 & 0 & 0 & 0 & Antarctica \\
\hline ARG & 0 & 2 & 0 & 2 & 0 & 5 & 0 & 0 & 0 & 0 & 2 & 9 & Argentina \\
\hline AUT & 3 & 21 & 33 & 36 & 3 & 0 & 0 & 0 & 0 & 0 & 0 & 16 & Austria \\
\hline AUS & 0 & 0 & 0 & 0 & 0 & 0 & 0 & 0 & 0 & 1 & 0 & 4 & Australia \\
\hline AZE & 0 & 0 & 0 & 0 & 0 & 0 & 0 & 0 & 0 & 0 & 0 & 1 & Azerbaijan \\
\hline $\mathrm{BIH}$ & 0 & 0 & 0 & 0 & 0 & 0 & 0 & 0 & 0 & 0 & 0 & 0 & Bosnia and Herzegovina \\
\hline BGD & 0 & 0 & 26 & 19 & 0 & 0 & 0 & 0 & 0 & 0 & 0 & 0 & Bangladesh \\
\hline BEL & 0 & 0 & 0 & 0 & 0 & 0 & 0 & 0 & 0 & 0 & 0 & 12 & Belgium \\
\hline BFA & 1 & 0 & 21 & 8 & 7 & 36 & 0 & 0 & 0 & 0 & 0 & 0 & Burkina Faso \\
\hline BGR & 0 & 0 & 0 & 0 & 0 & 0 & 0 & 0 & 0 & 0 & 0 & 0 & Bulgaria \\
\hline BDI & 0 & 0 & 0 & 0 & 0 & 0 & 0 & 0 & 0 & 0 & 0 & 0 & Burundi \\
\hline BEN & 0 & 3 & 8 & 8 & 3 & 18 & 0 & 0 & 0 & 0 & 0 & 0 & Benin \\
\hline BRN & 0 & 0 & 0 & 0 & 0 & 0 & 0 & 0 & 0 & 0 & 0 & 100 & Brunei Darussalam \\
\hline $\mathrm{BOL}$ & 0 & 0 & 0 & 0 & 0 & 0 & 0 & 13 & 13 & 9 & 11 & 67 & Bolivia \\
\hline BRA & 0 & 0 & 0 & 0 & 0 & 0 & 1 & 4 & 4 & 6 & 20 & 57 & Brazil \\
\hline BHS & 0 & 0 & 0 & 0 & 0 & 0 & 0 & 0 & 0 & 0 & 0 & 0 & Bahamas \\
\hline BTN & 0 & 54 & 0 & 8 & 0 & 0 & 0 & 0 & 0 & 0 & 15 & 85 & Bhutan \\
\hline BWA & 0 & 0 & 0 & 0 & 0 & 0 & 0 & 0 & 0 & 0 & 0 & 0 & Botswana \\
\hline BLR & 0 & 6 & 0 & 9 & 0 & 0 & 0 & 0 & 0 & 0 & 0 & 0 & Belarus \\
\hline $\mathrm{BLZ}$ & 0 & 0 & 0 & 0 & 0 & 0 & 0 & 0 & 0 & 0 & 0 & 0 & Belize \\
\hline CAN & 12 & 38 & 25 & 52 & 5 & 4 & 0 & 0 & 0 & 0 & 0 & 15 & Canada \\
\hline COD & 1 & 23 & 0 & 9 & 0 & 0 & 0 & 0 & 0 & 0 & 20 & 26 & Congo DRC \\
\hline CAF & 2 & 12 & 5 & 19 & 1 & 1 & 0 & 0 & 0 & 0 & 0 & 8 & Central African Republic \\
\hline COG & 2 & 31 & 0 & 4 & 0 & 0 & 0 & 0 & 0 & 0 & 4 & 71 & Congo \\
\hline $\mathrm{CHE}$ & 0 & 66 & 66 & 78 & 0 & 0 & 0 & 0 & 0 & 0 & 0 & 11 & Switzerland \\
\hline CIV & 0 & 0 & 5 & 1 & 0 & 1 & 0 & 0 & 0 & 0 & 3 & 2 & CÃ'te d'Ivoire \\
\hline COK & 0 & 0 & 0 & 0 & 0 & 0 & 0 & 0 & 0 & 0 & 0 & 0 & Cook Islands \\
\hline $\mathrm{CHL}$ & 0 & 3 & 0 & 2 & 0 & 0 & 0 & 0 & 0 & 1 & 0 & 29 & Chile \\
\hline CMR & 1 & 18 & 1 & 6 & 0 & 3 & 0 & 0 & 0 & 0 & 20 & 44 & Cameroon \\
\hline $\mathrm{CHN}$ & 1 & 11 & 4 & 21 & 1 & 3 & 0 & 0 & 0 & 0 & 4 & 17 & China \\
\hline $\mathrm{COL}$ & 1 & 19 & 0 & 2 & 0 & 0 & 0 & 0 & 0 & 0 & 10 & 52 & Colombia \\
\hline $\mathrm{CRI}$ & 0 & 7 & 0 & 0 & 0 & 0 & 0 & 0 & 0 & 0 & 0 & 53 & Costa Rica \\
\hline CUB & 0 & 0 & 0 & 0 & 0 & 0 & 0 & 0 & 0 & 0 & 0 & 0 & Cuba \\
\hline CPV & 0 & 0 & 0 & 0 & 0 & 0 & 0 & 0 & 0 & 0 & 0 & 0 & Cabo Verde \\
\hline CYP & 0 & 0 & 0 & 0 & 0 & 0 & 0 & 0 & 0 & 0 & 0 & 100 & Cyprus \\
\hline CZE & 0 & 13 & 3 & 40 & 3 & 0 & 0 & 0 & 0 & 0 & 0 & 0 & Czech Republic \\
\hline DEU & 0 & 20 & 8 & 26 & 4 & 0 & 0 & 0 & 0 & 0 & 0 & 0 & Germany \\
\hline DJI & 0 & 0 & 0 & 0 & 0 & 43 & 0 & 0 & 0 & 0 & 0 & 0 & Djibouti \\
\hline DNK & 3 & 0 & 58 & 51 & 24 & 0 & 0 & 0 & 0 & 0 & 0 & 0 & Denmark \\
\hline
\end{tabular}




\begin{tabular}{|c|c|c|c|c|c|c|c|c|c|c|c|c|c|}
\hline $\mathrm{DOM}$ & 0 & 0 & 0 & 0 & 0 & 0 & 0 & 0 & 0 & 0 & 0 & 6 & Dominican Republic \\
\hline $\mathrm{DZA}$ & 0 & 0 & 0 & 0 & 0 & 0 & 0 & 0 & 0 & 0 & 0 & 1 & Algeria \\
\hline ECU & 0 & 33 & 0 & 2 & 0 & 0 & 0 & 0 & 0 & 0 & 2 & 58 & Ecuador \\
\hline EST & 0 & 7 & 0 & 37 & 0 & 0 & 0 & 0 & 0 & 0 & 0 & 4 & Estonia \\
\hline EGY & 1 & 2 & 2 & 1 & 1 & 1 & 0 & 0 & 0 & 0 & 0 & 0 & Egypt \\
\hline ERI & 0 & 0 & 0 & 0 & 0 & 5 & 0 & 0 & 0 & 0 & 0 & 0 & Eritrea \\
\hline ESP & 0 & 0 & 0 & 0 & 0 & 0 & 0 & 0 & 0 & 3 & 0 & 17 & Spain \\
\hline ETH & 0 & 1 & 7 & 9 & 3 & 22 & 0 & 0 & 0 & 0 & 0 & 0 & Ethiopia \\
\hline FIN & 52 & 87 & 53 & 99 & 11 & 0 & 0 & 0 & 0 & 0 & 0 & 0 & Finland \\
\hline FJI & 0 & 0 & 0 & 0 & 0 & 0 & 0 & 0 & 0 & 0 & 0 & 0 & Fiji \\
\hline FLK & 0 & 0 & 0 & 0 & 0 & 0 & 0 & 0 & 0 & 0 & 0 & 50 & Falkland Islands \\
\hline FRO & 0 & 0 & 0 & 0 & 0 & 0 & 0 & 0 & 0 & 0 & 0 & 0 & Faroe Islands \\
\hline FRA & 0 & 3 & 1 & 9 & 0 & 0 & 0 & 0 & 0 & 2 & 0 & 12 & France \\
\hline GAB & 5 & 60 & 0 & 0 & 0 & 0 & 0 & 0 & 0 & 0 & 2 & 87 & Gabon \\
\hline GBR & 12 & 38 & 34 & 30 & 0 & 0 & 0 & 0 & 0 & 0 & 0 & 4 & United Kingdom \\
\hline GEO & 0 & 0 & 0 & 0 & 0 & 0 & 0 & 0 & 0 & 0 & 0 & 7 & Georgia \\
\hline GUF & 0 & 0 & 0 & 0 & 0 & 0 & 0 & 0 & 0 & 0 & 0 & 15 & French Guiana \\
\hline GHA & 0 & 0 & 11 & 8 & 0 & 0 & 0 & 0 & 0 & 0 & 0 & 0 & Ghana \\
\hline GRL & 0 & 0 & 1 & 2 & 1 & 1 & 0 & 0 & 0 & 0 & 0 & 0 & Greenland \\
\hline GMB & 0 & 0 & 0 & 0 & 0 & 0 & 0 & 0 & 0 & 0 & 0 & 0 & Gambia \\
\hline GIN & 0 & 1 & 5 & 1 & 0 & 0 & 0 & 0 & 0 & 0 & 0 & 12 & Guinea \\
\hline GLP & 0 & 0 & 0 & 0 & 0 & 0 & 0 & 0 & 0 & 0 & 0 & 0 & Guadeloupe \\
\hline GNQ & 0 & 89 & 0 & 0 & 0 & 0 & 0 & 0 & 0 & 0 & 0 & 78 & Equatorial Guinea \\
\hline GRC & 0 & 0 & 0 & 0 & 0 & 0 & 0 & 0 & 0 & 0 & 0 & 10 & Greece \\
\hline SGS & 0 & 0 & 0 & 0 & 0 & 0 & 0 & 0 & 0 & 0 & 0 & 0 & $\begin{array}{l}\text { South Georgia and South } \\
\text { Sandwich Islands }\end{array}$ \\
\hline GTM & 0 & 0 & 0 & 0 & 0 & 0 & 0 & 0 & 0 & 0 & 0 & 39 & Guatemala \\
\hline GNB & 0 & 0 & 0 & 0 & 0 & 0 & 0 & 0 & 0 & 0 & 0 & 0 & Guinea-Bissau \\
\hline GUY & 0 & 0 & 0 & 0 & 0 & 0 & 0 & 0 & 0 & 5 & 5 & 76 & Guyana \\
\hline HND & 0 & 0 & 0 & 0 & 0 & 0 & 0 & 0 & 0 & 3 & 0 & 67 & Honduras \\
\hline HRV & 0 & 0 & 0 & 0 & 0 & 0 & 0 & 0 & 0 & 0 & 0 & 0 & Croatia \\
\hline $\mathrm{HTI}$ & 0 & 0 & 0 & 0 & 0 & 0 & 0 & 0 & 0 & 0 & 0 & 8 & Haiti \\
\hline HUN & 0 & 0 & 0 & 0 & 0 & 0 & 0 & 0 & 0 & 0 & 0 & 0 & Hungary \\
\hline IDN & 0 & 16 & 1 & 4 & 0 & 0 & 0 & 0 & 0 & 1 & 11 & 58 & Indonesia \\
\hline IRL & 0 & 13 & 31 & 18 & 0 & 0 & 0 & 0 & 0 & 0 & 0 & 5 & Ireland \\
\hline ISR & 0 & 0 & 0 & 0 & 0 & 0 & 0 & 0 & 0 & 0 & 0 & 0 & Israel \\
\hline IND & 3 & 3 & 8 & 16 & 2 & 7 & 0 & 0 & 0 & 0 & 1 & 6 & India \\
\hline IRQ & 0 & 0 & 0 & 0 & 0 & 0 & 0 & 0 & 0 & 0 & 2 & 1 & Iraq \\
\hline IRN & 0 & 0 & 0 & 0 & 0 & 0 & 0 & 0 & 0 & 0 & 0 & 0 & Iran \\
\hline ISL & 3 & 4 & 58 & 87 & 46 & 7 & 0 & 0 & 0 & 0 & 0 & 0 & Iceland \\
\hline ITA & 0 & 1 & 0 & 1 & 0 & 0 & 0 & 0 & 0 & 0 & 0 & 3 & Italy \\
\hline JAM & 0 & 0 & 0 & 0 & 0 & 0 & 0 & 0 & 0 & 0 & 0 & 0 & Jamaica \\
\hline
\end{tabular}




\begin{tabular}{|c|c|c|c|c|c|c|c|c|c|c|c|c|c|}
\hline JOR & 0 & 0 & 0 & 0 & 0 & 0 & 0 & 0 & 0 & 0 & 0 & 0 & Jordan \\
\hline JPN & 0 & 90 & 1 & 4 & 0 & 0 & 0 & 0 & 0 & 0 & 8 & 75 & Japan \\
\hline KEN & 0 & 0 & 0 & 13 & 1 & 29 & 0 & 0 & 0 & 0 & 0 & 0 & Kenya \\
\hline KGZ & 0 & 0 & 0 & 19 & 0 & 0 & 0 & 0 & 0 & 0 & 0 & 8 & Kyrgyzstan \\
\hline KHM & 0 & 0 & 0 & 0 & 0 & 0 & 0 & 0 & 0 & 0 & 13 & 50 & Cambodia \\
\hline KIR & 0 & 0 & 0 & 0 & 0 & 0 & 0 & 0 & 0 & 0 & 0 & 0 & Kiribati \\
\hline COM & 0 & 0 & 0 & 0 & 0 & 0 & 0 & 0 & 0 & 0 & 0 & 0 & Comoros \\
\hline PRK & 0 & 15 & 0 & 0 & 0 & 0 & 0 & 0 & 0 & 0 & 8 & 58 & North Korea \\
\hline KOR & 0 & 53 & 0 & 0 & 0 & 0 & 0 & 0 & 0 & 0 & 0 & 64 & South Korea \\
\hline KWT & 0 & 0 & 0 & 0 & 0 & 0 & 0 & 0 & 0 & 0 & 0 & 0 & Kuwait \\
\hline KAZ & 0 & 0 & 1 & 4 & 0 & 0 & 0 & 0 & 0 & 0 & 0 & 0 & Kazakhstan \\
\hline LAO & 0 & 0 & 0 & 0 & 0 & 0 & 0 & 0 & 0 & 0 & 19 & 59 & Laos \\
\hline LBN & 0 & 0 & 0 & 0 & 0 & 0 & 0 & 0 & 0 & 0 & 0 & 75 & Lebanon \\
\hline LKA & 0 & 9 & 9 & 59 & 0 & 0 & 0 & 0 & 0 & 0 & 0 & 0 & Sri Lanka \\
\hline LBR & 0 & 6 & 0 & 0 & 0 & 0 & 0 & 0 & 0 & 0 & 10 & 10 & Liberia \\
\hline LSO & 0 & 0 & 0 & 0 & 0 & 0 & 0 & 0 & 0 & 0 & 0 & 58 & Lesotho \\
\hline LTU & 31 & 36 & 3 & 38 & 0 & 0 & 0 & 0 & 0 & 0 & 0 & 0 & Lithuania \\
\hline LUX & 0 & 100 & 0 & 100 & 0 & 0 & 0 & 0 & 0 & 0 & 0 & 0 & Luxembourg \\
\hline LVA & 0 & 6 & 0 & 66 & 0 & 0 & 0 & 0 & 0 & 0 & 0 & 0 & Latvia \\
\hline LBY & 0 & 0 & 0 & 0 & 0 & 0 & 0 & 0 & 0 & 0 & 0 & 0 & Libya \\
\hline MAR & 0 & 0 & 0 & 0 & 0 & 0 & 0 & 0 & 0 & 5 & 0 & 17 & Morocco \\
\hline MDA & 0 & 0 & 0 & 0 & 0 & 0 & 0 & 0 & 0 & 0 & 0 & 0 & Moldova \\
\hline MNE & 0 & 0 & 0 & 0 & 0 & 0 & 0 & 0 & 0 & 0 & 0 & 0 & Montenegro \\
\hline MDG & 2 & 0 & 0 & 0 & 0 & 0 & 0 & 0 & 0 & 12 & 14 & 55 & Madagascar \\
\hline MKD & 0 & 0 & 0 & 0 & 0 & 0 & 0 & 0 & 0 & 0 & 0 & 0 & $\begin{array}{l}\text { The Former Yugoslav Republic } \\
\text { Macedonia }\end{array}$ \\
\hline $\mathrm{MLI}$ & 0 & 0 & 6 & 4 & 1 & 2 & 0 & 0 & 0 & 0 & 0 & 1 & Mali \\
\hline MMR & 0 & 2 & 0 & 0 & 0 & 0 & 0 & 0 & 0 & 1 & 7 & 38 & Myanmar \\
\hline MNG & 0 & 2 & 0 & 5 & 0 & 1 & 0 & 0 & 0 & 0 & 0 & 2 & Mongolia \\
\hline MRT & 0 & 0 & 0 & 2 & 0 & 0 & 0 & 0 & 0 & 0 & 0 & 0 & Mauritania \\
\hline MUS & 0 & 0 & 0 & 0 & 0 & 0 & 0 & 0 & 0 & 0 & 0 & 0 & Mauritius \\
\hline MWI & 0 & 0 & 0 & 0 & 0 & 0 & 0 & 0 & 0 & 0 & 0 & 39 & Malawi \\
\hline MEX & 0 & 0 & 0 & 0 & 0 & 0 & 0 & 0 & 0 & 0 & 1 & 14 & Mexico \\
\hline MYS & 0 & 20 & 1 & 1 & 0 & 0 & 0 & 0 & 0 & 0 & 7 & 77 & Malaysia \\
\hline $\mathrm{MOZ}$ & 0 & 0 & 0 & 0 & 0 & 0 & 0 & 0 & 0 & 0 & 1 & 19 & Mozambique \\
\hline NAM & 0 & 0 & 0 & 0 & 0 & 0 & 0 & 0 & 0 & 0 & 0 & 1 & Namibia \\
\hline $\mathrm{NCL}$ & 0 & 0 & 0 & 0 & 0 & 0 & 0 & 0 & 0 & 0 & 0 & 0 & New Caledonia \\
\hline NER & 0 & 0 & 11 & 8 & 13 & 22 & 0 & 0 & 0 & 0 & 0 & 0 & Niger \\
\hline NGA & 2 & 1 & 24 & 11 & 16 & 34 & 0 & 0 & 0 & 0 & 0 & 0 & Nigeria \\
\hline $\mathrm{NIC}$ & 0 & 0 & 0 & 0 & 0 & 0 & 0 & 0 & 0 & 4 & 0 & 59 & Nicaragua \\
\hline NLD & 0 & 0 & 0 & 0 & 0 & 0 & 0 & 0 & 0 & 0 & 0 & 0 & Netherlands \\
\hline NOR & 14 & 38 & 70 & 73 & 10 & 0 & 0 & 0 & 0 & 0 & 0 & 14 & Norway \\
\hline
\end{tabular}




\begin{tabular}{|c|c|c|c|c|c|c|c|c|c|c|c|c|c|}
\hline$\overline{N P L}$ & 0 & 19 & 2 & 4 & 0 & 0 & 0 & 0 & 0 & 0 & 0 & 19 & Nepal \\
\hline NZL & 2 & 21 & 0 & 7 & 0 & 0 & 0 & 0 & 0 & 0 & 0 & 32 & New Zealand \\
\hline OMN & 0 & 0 & 0 & 0 & 0 & 0 & 0 & 0 & 0 & 0 & 0 & 0 & Oman \\
\hline PAN & 0 & 4 & 0 & 4 & 0 & 0 & 0 & 0 & 0 & 0 & 0 & 25 & Panama \\
\hline PER & 0 & 9 & 0 & 2 & 0 & 0 & 0 & 0 & 0 & 0 & 33 & 76 & Peru \\
\hline PYF & 0 & 0 & 0 & 0 & 0 & 0 & 0 & 0 & 0 & 0 & 0 & 0 & French Polynesia \\
\hline PNG & 0 & 8 & 0 & 2 & 0 & 0 & 0 & 0 & 0 & 0 & 19 & 62 & Papua New Guinea \\
\hline PHL & 0 & 0 & 0 & 0 & 0 & 0 & 0 & 0 & 0 & 0 & 15 & 59 & Philippines \\
\hline PAK & 0 & 1 & 0 & 5 & 2 & 3 & 0 & 0 & 0 & 0 & 0 & 0 & Pakistan \\
\hline POL & 0 & 2 & 0 & 0 & 0 & 0 & 0 & 0 & 0 & 0 & 0 & 0 & Poland \\
\hline PRI & 0 & 0 & 0 & 0 & 0 & 0 & 0 & 0 & 0 & 0 & 0 & 0 & Puerto Rico \\
\hline PSE & 0 & 0 & 0 & 0 & 0 & 0 & 0 & 0 & 0 & 0 & 0 & 0 & Palestinian Territory \\
\hline PRT & 0 & 0 & 0 & 0 & 0 & 0 & 0 & 0 & 0 & 2 & 0 & 31 & Portugal \\
\hline PRY & 0 & 1 & 0 & 0 & 0 & 2 & 0 & 1 & 1 & 6 & 4 & 1 & Paraguay \\
\hline QAT & 0 & 0 & 0 & 0 & 0 & 0 & 0 & 0 & 0 & 0 & 0 & 0 & Qatar \\
\hline REU & 0 & 0 & 0 & 0 & 0 & 0 & 0 & 0 & 0 & 0 & 0 & 0 & RÃ@)union \\
\hline ROU & 0 & 0 & 0 & 0 & 0 & 0 & 0 & 0 & 0 & 1 & 0 & 1 & Romania \\
\hline SRB & 0 & 0 & 0 & 0 & 0 & 0 & 0 & 0 & 0 & 0 & 0 & 0 & Serbia \\
\hline RUS & 22 & 51 & 31 & 68 & 16 & 7 & 0 & 0 & 0 & 0 & 0 & 3 & Russian Federation \\
\hline RWA & 0 & 40 & 0 & 0 & 0 & 0 & 0 & 0 & 0 & 0 & 0 & 0 & Rwanda \\
\hline SAU & 0 & 0 & 0 & 0 & 0 & 0 & 0 & 0 & 0 & 0 & 0 & 0 & Saudi Arabia \\
\hline SLB & 0 & 0 & 0 & 0 & 0 & 0 & 0 & 0 & 0 & 0 & 0 & 20 & Solomon Islands \\
\hline SDN & 0 & 0 & 4 & 3 & 1 & 7 & 0 & 0 & 0 & 0 & 0 & 0 & Sudan \\
\hline SWE & 19 & 60 & 55 & 83 & 11 & 0 & 0 & 0 & 0 & 0 & 0 & 4 & Sweden \\
\hline SVN & 0 & 0 & 0 & 0 & 0 & 0 & 0 & 0 & 0 & 0 & 0 & 0 & Slovenia \\
\hline SJM & 0 & 0 & 0 & 0 & 0 & 1 & 0 & 0 & 0 & 0 & 0 & 0 & Jan Mayen \\
\hline SVK & 0 & 0 & 0 & 0 & 0 & 0 & 0 & 0 & 0 & 0 & 0 & 0 & Slovakia \\
\hline SLE & 12 & 24 & 8 & 0 & 0 & 0 & 0 & 0 & 0 & 0 & 0 & 12 & Sierra Leone \\
\hline SEN & 0 & 0 & 0 & 0 & 0 & 0 & 0 & 0 & 0 & 0 & 0 & 10 & Senegal \\
\hline SOM & 0 & 0 & 0 & 31 & 0 & 66 & 0 & 0 & 0 & 0 & 0 & 0 & Somalia \\
\hline SUR & 0 & 0 & 0 & 0 & 0 & 0 & 0 & 0 & 0 & 0 & 0 & 43 & Suriname \\
\hline SSD & 1 & 0 & 5 & 10 & 2 & 0 & 0 & 0 & 0 & 0 & 0 & 1 & South Sudan \\
\hline STP & 0 & 0 & 0 & 0 & 0 & 0 & 0 & 0 & 0 & 0 & 0 & 0 & Sao Tome and Principe \\
\hline SLV & 0 & 0 & 0 & 0 & 0 & 0 & 0 & 0 & 0 & 0 & 0 & 100 & El Salvador \\
\hline SYR & 0 & 0 & 0 & 0 & 0 & 0 & 0 & 0 & 0 & 1 & 0 & 3 & Syria \\
\hline SWZ & 0 & 0 & 0 & 0 & 0 & 0 & 0 & 0 & 0 & 0 & 0 & 0 & Swaziland \\
\hline TCD & 2 & 0 & 14 & 10 & 8 & 12 & 0 & 0 & 0 & 0 & 0 & 0 & Chad \\
\hline ATF & 0 & 0 & 0 & 0 & 0 & 0 & 0 & 0 & 0 & 0 & 0 & 0 & French Southern Territories \\
\hline TGO & 0 & 6 & 22 & 22 & 6 & 0 & 0 & 0 & 0 & 0 & 0 & 0 & Togo \\
\hline THA & 0 & 0 & 1 & 1 & 0 & 0 & 0 & 0 & 0 & 0 & 2 & 3 & Thailand \\
\hline TJK & 0 & 0 & 0 & 2 & 0 & 0 & 0 & 0 & 0 & 0 & 0 & 2 & Tajikistan \\
\hline
\end{tabular}




\begin{tabular}{|l|r|r|r|r|r|r|r|r|r|r|r|r|l|}
\hline TLS & 0 & 0 & 0 & 0 & 0 & 0 & 0 & 0 & 0 & 0 & 0 & 0 & Timor-Leste \\
\hline TKM & 0 & 0 & 0 & 0 & 0 & 0 & 0 & 0 & 0 & 0 & 0 & 0 & Turkmenistan \\
\hline TUN & 0 & 0 & 0 & 0 & 0 & 0 & 0 & 0 & 0 & 0 & 0 & 12 & Tunisia \\
\hline TUR & 0 & 0 & 0 & 1 & 0 & 0 & 0 & 0 & 0 & 2 & 0 & 15 & Turkey \\
\hline TTO & 0 & 0 & 0 & 0 & 0 & 0 & 0 & 0 & 0 & 0 & 0 & 100 & Trinidad and Tobago \\
\hline TZA & 0 & 1 & 0 & 13 & 2 & 25 & 0 & 0 & 0 & 0 & 5 & 2 & Tanzania \\
\hline UKR & 0 & 0 & 0 & 0 & 0 & 0 & 0 & 0 & 0 & 0 & 0 & 1 & Ukraine \\
\hline UGA & 0 & 2 & 0 & 20 & 2 & 22 & 0 & 0 & 0 & 0 & 0 & 0 & Uganda \\
\hline USA & 8 & 17 & 9 & 21 & 5 & 1 & 0 & 0 & 0 & 0 & 0 & 11 & United States \\
\hline URY & 0 & 0 & 0 & 1 & 0 & 0 & 0 & 0 & 0 & 0 & 0 & 0 & Uruguay \\
\hline UZB & 0 & 0 & 0 & 0 & 0 & 0 & 0 & 0 & 0 & 0 & 0 & 1 & Uzbekistan \\
\hline VCT & 0 & 0 & 0 & 0 & 0 & 0 & 0 & 0 & 0 & 0 & 0 & 0 & Saint Vincent and the Grenadine \\
\hline VEN & 0 & 0 & 0 & 0 & 0 & 0 & 0 & 0 & 0 & 0 & 12 & 80 & Venezuela \\
\hline VIR & 0 & 0 & 0 & 0 & 0 & 0 & 0 & 0 & 0 & 0 & 0 & 0 & US Virgin Islands \\
\hline VNM & 0 & 0 & 0 & 0 & 0 & 0 & 0 & 0 & 0 & 0 & 11 & 46 & Vietnam \\
\hline VUT & 0 & 0 & 0 & 0 & 0 & 0 & 0 & 0 & 0 & 0 & 0 & 0 & Vanuatu \\
\hline WS & 0 & 0 & 0 & 0 & 0 & 0 & 0 & 0 & 0 & 0 & 0 & 0 & Samoa \\
M & & & & & & & & & & & & & \\
\hline YEM & 0 & 0 & 0 & 0 & 0 & 0 & 0 & 0 & 0 & 0 & 0 & 0 & Yemen \\
\hline ZAF & 0 & 0 & 0 & 0 & 0 & 0 & 0 & 0 & 0 & 1 & 1 & 12 & South Africa \\
\hline ZMB & 0 & 0 & 0 & 0 & 0 & 0 & 0 & 0 & 0 & 2 & 4 & 66 & Zambia \\
\hline ZWE & 0 & 0 & 0 & 0 & 1 & 0 & 0 & 0 & 0 & 0 & 0 & 1 & Zimbabwe \\
\hline
\end{tabular}

